ITI. FILE COE

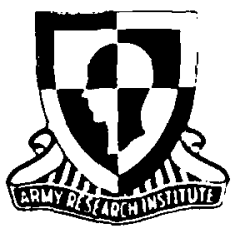

Research Product 88-40

$N$
0
0
1
1

\title{
A Handbook for Producing Classroom Vugraphs
}

September 1988

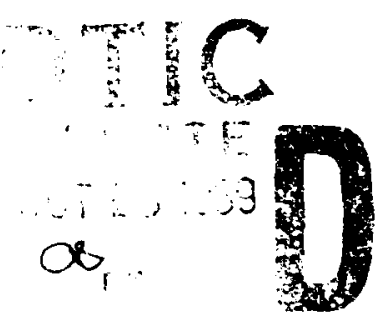

Logistics Training Technologies Technical Area Training Research Laboratory

U.S. Army Research Institute for the Behavioral and Social Sciences 


\section{REPORT DOCUMENTATION PAGE}

1a. REPORT SECURITY CLASSIFICATION
UnClaSSif ied
\begin{tabular}{l|} 
2a. SECURITY CLASSIFICATION AUTHORITY \\
--
\end{tabular}
$\begin{aligned} & \text { 2b. DECLASSIFICATION/DOWNGRADING SCHEDULE } \\
& --\end{aligned}$

ARI Research Product $88-40$

6a. NAME OF PERFORMING ORGANIZATION Ui. S. Army Research Institute for the Behavioral and Social Sciences

6C. ADDRESS (City, State, and ZIP Code)

5001 Eisenhower Avenue

Alexandria, VA 22333-5600

8a. NAME OF FUNDING / SPONSORING ORGANIZATION U.S. Army Research Institute for the Rehavicra? and Social Sciences

8c ADDRESS (City, State, and ZIP Code)

5001 Eisenhower Avenue Alexandria, VA 22333-5600

11. TITLE (Inciude Security Classification)

A Handbook for Producing Classroom Vugraphs

12. PERSONAL AUTHOR(S)

Ramsay, Douglas A., and Mirabella, Angelo

\begin{tabular}{l|l}
\hline 13a. TYPE OF REPORT & 13b. TIME COVERED \\
Final & FROM $87 / 09$ \\
\hline
\end{tabular}

16. SUPPLEMENTARY NOTATION

-

\begin{tabular}{|l|l|l|}
\hline 17. & \multicolumn{2}{|c|}{ COSATI CODES } \\
\hline FIELO & GROUP & SUB.GROUP \\
\hline & & \\
\hline & & \\
\hline
\end{tabular}

18. SUBJECT TERMS (Continue on reverse if necessary and identify by block number)

Military training

Visual aids

Classroom training

Training aids

b. RESTRICTIVE MARKINGS

3 DISTRIBUTION / AVAILABILITY OF REPORT

Approved for public release;

distribution is unlimited.

5. MONITORING ORGANIZATIOIV REPORT NUMBER(S)

7a. NAME OF MONITORING ORGANIZATION

(2)

b. ADDRESS (City, State, and ZIP Code)

19. ABSTRACT (Continue on reverse if necessary and identify by block number)

- The handbook provides simple rules and suggestions for instructors and training developers producing vugraphs (overhead projection transparencies) for use in Army classrooms. Use of the handbook requires only simple cut-and-paste materials and access to a copying machine capable of handling film transparencies.

20. DISTRIBUTION / AVAILABILITY OF ABSTRACT $\Theta$ UNCLASSIFIEDNNLIMITED $\square$ SAME AS RPT

22a. NAME OF RESPONSIBLE INDIVIDUAL

Edgar M. Johnson
21. ABSTRACT SECURITY CLASSIFICATION

Unclassified

22b TELEPHONE (Include Ared COde) 22c. OFFICE SYMBOL (703) 274-8635

FERI-ZT 


\title{
U.S. ARMY RESEARCH INSTITUTE \\ FOR THE BEHAVIORAL AND SOCIAL SCIENCES
}

\author{
A Field Operating Agency Under the Jurisdiction \\ of the Deputy Chief of Staff for Personnel
}

EDGAR M. JOHNSON

JON W. BLADES

Technical Director

COL, IN

Commanding

Technical review by

Douglas Dressel

Jonathan E. Frederick

Richard P. Kern

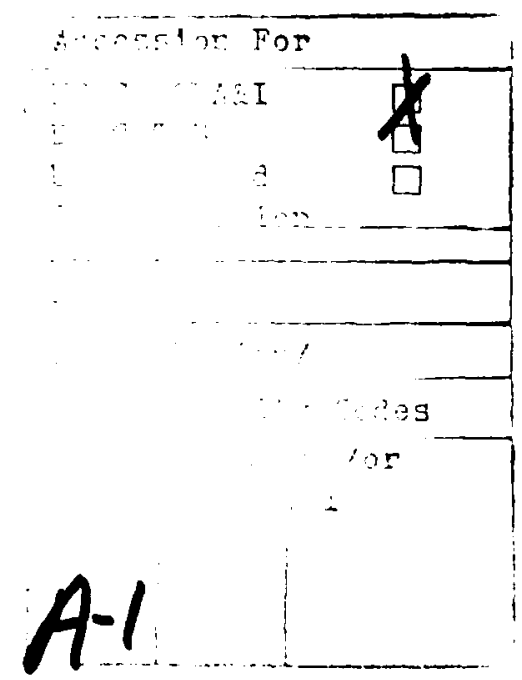

\section{NOTICES}

FINAL DISPOSITION: This Research Product may be destroyed when it is no longer needed. Please do not return it to the U.S. Army Research Institute for the Behavioral and Social Sciences.

NOTE: This Research Product is not to be construed as an official Department of the Army document, unless so designated by other authorized dociments. 
Research Product 88-40

\section{A Handbook for Producing Classroom Vugraphs}

Douglas A. Ramsay and Angelo Mirabella

U.S. Army Research Institute

Logistics Training Technologies Technical Area Robert J. Seidel, Chief

\section{Training Research Laboratory Jack H. Hiller, Director}

U.S. Army Research Institute for the Behavioral and Social Sciences

5001 Eisenhower Avenue, Alexandria, Virginia 22333-5600

Office, Deputy Chief of Staff for Personnel

Department of the Army

September 1988 
The U.S. Army Research Institute for the Behavioral and Social Suiences (ARI), in cooperation with Training and Doctrine Command (TRADOC) and its schools, performs research and development on ways to achieve cost-effective training. In 1987, ARI joined with TRADOC and the U.S. Army Ordnance Center and School (USAOC\&S) in a partnership at Aberdeen Proving Ground (APG), Maryland, to identify and solve maintenance training problems. The partnership was defined by a memorandum of understanding (MOU) entitled "Establishment of a Training Technology Field Activity (TTFA) at the USAOC\&S," and dated 10 May 1987.

While reviewing the training practices of one of the courses at USAOC\&S, researchers became aware of the need for improvement of visual aids. This handbook was devised to assist instructors in making their own transparencies for use in the classroom. The work was carried out as part of Task 344 by members of the Logistics Training Technologies Technical Area of the Training Research Laboratory.

This and other products of the TTFA were briefed to the Deputy Assistant Commandant, USAOC\&S, in october 1988. The handbook will be used to revise visual aid materials, provide a standard for such materials, and help train instructors in preparation of classroom vugraphs. Its value was recognized by MG Ball, Commandant, USAOC\&S, in letters of appreciation to the authors.

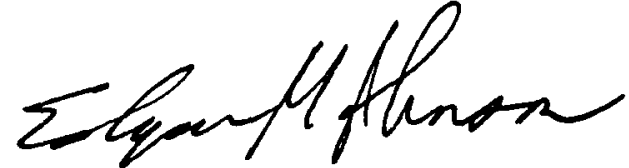

EDGAR M. JOHNSON

Technical Director 
The authors wish to acknowledge the assistance of the following people in developing this product: MAJ Gary Addison and Mr. Harold Lane, the Director and Assistant Director of the Wheel Vehicle Department, and the many military and civilian instructors who graciously tolerated our presence in their classrooms; Dr. Mahina Kundu and Mr. Jim Dees of the New Technology Branch in the Department of Training and Doctrine, who were our PoCs at the ordnance Center and School; Mr. Herbert Warzecha, Chief of the Graphics section in the Training Aids Branch of USAOC\&S; and Dr. Millie Abell of TRADOC. 
A HANDBOOK FOR PRODUCING CLASSROOM VUGRAPHS

CONTENTS

Page

INTRODUCTION • . . . . . . . . . . . . . . . . . . . . 1

What Is the Handbook About? . . . . . . . . . . . . 1

Who Should Use the Handbook? . . . . . . . . . . . . . . 1

What Does the Handbook Do? . . . . . . . . . . . . . . 1

OVERVIEW . . . . . . . . . . . . . . . . . . . . . . . 3

Visual Aids in the Classroom . . . . . . . . . . . . . 3

An Approach to Developing Good Visual Aids . . . . . . . 3

GETTING STARTED • • • • • • • • • • • • • • • • • • • 5

The POI . . . . . . . . . . . . . . . . . . . 5

Determining Need . . . . . . . . . . . . . . . . 5

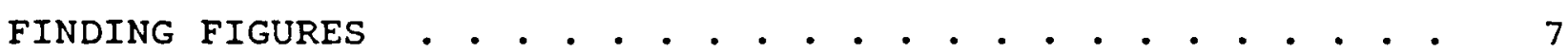

Book Figures Versus Projected Image . . . . . . . . . . 7

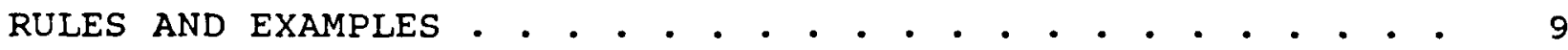

TIPS FOR IMPROVING GRAPHICS . . . . . . . . . . . . . . . 33

Highlighting . . . . . . . . . . . . . . . . . . 33

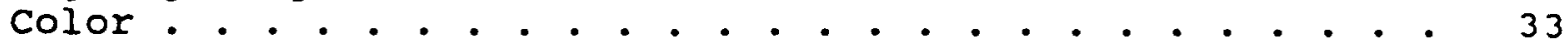

Enlargement . . . . . . . . . . . . . . . . . . 37

Miscellaneous . . . . . . . . . . . . . . . . . . 37

PROCEDURES . . . . . . . . . . . . . . . . . . . . . . 41

Materials . . . . . . . . . . . . . . . . . . . 41

Steps to follow . . . . . . . . . . . . . . . . . . . . . 41

Vugraph Checklist. . . . . . . . . . . . . . . . . 48

USING VISUAL AIDS EFFECTIVELY • • • • • . • • • • • • • • • 49

\begin{tabular}{lllllll} 
APPENDIX 1. TEACHING POINTS AND PERFORMANCE ORIENTED \\
TRAINING \\
\hline
\end{tabular}

2. COMPUTER AIDED REVISION OF EXISTING GRAPHICS • B-1 


\section{LIST OF FIGURES}

Figure 1.0 Good printed material that makes a poor vugraph . . . . . . . . . . . . . . 8

2.0 Violation of Rule 1: Too much information around the graphic.. . . . . . . . . . . 10

3.0 Application of Rule 1 . . . . . . . . . . . 11

4.0 Teaching point clear (Rule 2), but too much information . . . . . . . . . . . . . 13

5.0 Teaching point clear, but still too much information . . . . . . . . . . . . . . 14

6.0 Teaching point clear, unneeded information cut . 15

7.0 Too many call-outs, poorly arranged . . . . . . 17

8.0 Correct number of call-outs, but still poorly

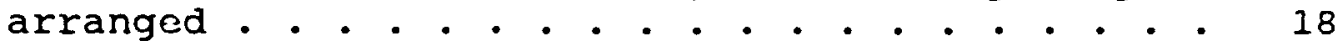

9.0 Correct number of call-outs, properly arranged . 19

10.0 Too much explanation . . . . . . . . . . 20

11.0 Lengthy explanation cut . . . . . . . . . 21

12.0 Example of poor use of photographs . . . . . . 22

13.0 Drawing as replacement for photograph . . . . . 23

14.0 Improved drawing as replacement for photograph . 25

15.0 Incorrect spatial orientation . . . . . . . . 26

16.0 Correct spatial orientation . . . . . . . . 27

17.0 Good spatial orientation but other rules

18.0 Clear graphic, but wrong spatial orientation . . 29

19.0 Clear graphic, good spatial orientation . . . 30

20.0 Clear graphic, good spatial orientation,
misinformation . . . . . . . . . . . . . 32 
Page

Figure 21.0 Need for highlighting . . . . . . . . . . . . 34

22.0 Use of highlighting to bring out details . . . 35

23.0 Need for highlighting to explain . . . . . . . 36

24.0 Use of highlighting to explain . . . . . . . 38

25.0 Book illustration enlarged for clearer

viewing . . . . . . . . . . . . . . . 39

26.0 Selecting material for vugraphs . . . . . . . 42

27.0 Initial cut and paste. . . . . . . . . . . 44

28.0 Eliminating unwanted material or arrangements . 45

29.0 Adding new material or arrangements . . . . . . 46

30.0 The final vugraph . . . . . . . . . . . . 47 


\title{
A HANDBOOK FOR PRODUCING CLASSROOM VUGRAPHS
}

\author{
INTRODUCTION
}

What Is the Handbook About?

The handbook is about selecting or constructing visuai aids for use in the Army classroom setting. By visual aids, we are talking about transparencies (or vugraphs, as we will call them) or $35 \mathrm{~mm}$ slides, both of which are projected on a screen at the front of the classroom. The emphasis will be on using figures or illustrations taken from books or Army publications such as technical or field manuals. Vugraphs are easily constructed by an instructor with access to an office copying machine, while 35 $\mathrm{mm}$ slides usually require the assistance of a Training Aids department. The final product of these two techniques, however, is the same--an image projected on a screen. The purpose of the handbook is to provide some easy-to-follow rules for producing vugraphs or slides that will help students learn.

Who Should Use the Handbook?

The handbook is aimed at the training developer or instructor who is producing lesson material for delivery in a classroom equipped with an overhead projector for vugraphs or a slide projector for $35 \mathrm{~mm}$ slides. Although a variety of visual aids are used in the Army classroom, including films, TV, mock-up models, chalkboards, and wallcharts, to name a few, we are only concerned with vugraphs and slides produced locally.

What Does the Handbook Do?

The handbook provides the user with a few simple rules for selecting illustrations in manuals and books that can then be turned into acceptable vugraphs or slides. Although we do not treat original artwork or drawings, the same rules can be applied in constructing them. The rules are illustrated by showing a number of examples drawn from actual Army material. Only the simplest of office supplies are needed to produce the figures shown in the handbook. 


\section{OVERVIEW}

Visual Aids in the Classroom

It may be worthwhile, at the start, to consider why we use visual aids in the classroom in the first place. They say, "One picture is worth a thousand words." That may be true but misleading. If the quality of a "picture" is poor or it is shown for too short a time, it may be worth only a fraction of a thousand words. Usually the instructor uses a picture to illustrate some point, but if the instructor's description is too hurried or poorly organized, the "picture" may be worth next to nothing.

Generally, the instructor uses pictures or graphics to illustrate information about objects or relationships between objects. The pictures may be realistic or simplified and, sometimes, symbolic representaions. These pictures are rarely self-explanatory and usually require a description or explanation to be given by the instructor.

The important thing to keep in mind when preparing illustrations for use in classroom training is what the student does or can do with the information. students try to boil down the informacion presented visually to some compact form, usually by taking notes for later recall or reference. Few students are so naturally endowed that they can retain visual images for a long time without some such assistance. There is abundant evidence from research to show that passive viewing of visual material does not result in long-term retention.

Vugraphs and slides are used everywhere in Army training, but with varying degrees of success. They are so common that they often cause problems which are overlooked. A typical problem occurs when the image on the screen is not clear, especially at the back of a large classroom. Graphs or slides made from book or manual illustrations often have too much information or detail but are used because they are easy to make. Even good, clear graphs or slides may not be effective teaching tools because they are not shown for a long enough period of time or receive an inadequate description by the instructor. Even poor lighting in the classroom or a dirty projector lens can reduce the effectiveness of a good illustration and make a poor illustration almost useless.

An Approach to Developing Good Visual Aids

There are two major considerations in constructing good vugraphs and slides. The rules we will present later are based 
largely on these two basic principles. The first of these we will call the main teaching point, or points. The material covered in the Army classroom is defined by the Program of Instruction, or POI. The POI specifies the scope of material to be covered while the individual Lesson Plan describes the teaching pojnts to be covered in more detail. A vugraph or slide should be chosen or constructed to illustrate a well-defined teaching point taken from the Lesson plan. It should be limited to and emphasize that teaching point and extraneous or "nice-to-have" material should be excluded. The second major concern is that the vugraph or slide should allow the student to grasp the main teaching point and do something with it--maise a sketch or take notes. Both of these considerations play important roles in deciding how much information is contained in an illustration, how it is presented or. the screen, and how the instructor uses it.

Our approach to developing good illustrations for projection in the classroom comes from an analysis of the classroom situation and some basic principles of human learning. First, as we pointed out earlier, vugraphs and slides are projected on a screen which, by necessity, is at varying distances from the students in the classroom. A second important but often overlooked fact is that the projected image is on the screen for a limited amount of time. Finally, the instructor usually has to describe or explain what is in the illustration. As for learning, students, as we all know, do not merely soak up everything they see and hear in the classroom. Teaching would be a snap if that were true. There are limits to the amount of information a person can absorb at any one time. Also, there is competition when two senses, hearir.g and seeing, are receiving information at the same time. Finally, people learn better by doing rather than passively receiving information. 
The POI

The Program of Instruction (POI) lays out the topics to be covered in a course, while the Lesson Plans lay out material to be covered in class. Lesson Plans also specify the training materials to be used including vugraphs and slides. For those of you who have to decide what visual aid to provide, the Lesson Plan is the source for determining the "Teaching Point" of each vugraph or slide. Ideally, any illustration you use shouid be narrowed down to the teaching point, for example, the electrical polarity of storage batteries, or the major parts of a military compass. Sometimes a major heading in a Lesson Plan needs to be broken down into smaller, easy-to-hardle, teaching points.

Determining Need

Not everything in the Lesson Plan needs to be covered by a visual aid. Figures are best used to picture "things" or objects such as Army equipment or parts of equipment. They are also used to show the relationships between things, such as a schematic wiring diagram. The instructor or training developer needs to decide if a visual aid will help get the teaching point across effectively. Once a decision has been made to use a vugraph or slide, the most important principle to follow is to SIMPLIFY. Focus on the main teaching point and restrict your figure to illustrating that point. The illustrations in this handbook will show you various ways to accomplish this important goal. 


\section{FINDING FIGURES}

Book Figures versus Projected Image

Illustrations and figures are not difficult to find. Books, magazines, and especially Army manuals are full of them. Figure 1 was taken from a recent issue of an Army Bulletin, Aviation Digest, and is a good example of the use of figures in printed material. The figure is used to illustrate the location of various parts on the AH-64A helicopter. The various labels (referred to as Call-outs) in the figure point to the different parts of the drive system which are then described in the text below the figure. There are several aspects of the use of a figure in this context which distinguish it from a (good) vugraph or slide. First, there is a lot of information presented here (17 labels or call-outs). Second, the reader has all the time in the world to look at the figure and read the accompanying text. Third, the size and clarity of the drawing (and the call-outs) is essentially the same for all viewers, that is, readers of the Bulletin.

As we have said before, slides and vugraphs result in a projected image on a screen. The image is available to the student in the classroom for only a relatively short period of time, at most a few minutes. Students at the back of the class have a different view from those in the front. Under these conditions, too much detail in a figure becomes a liability. The clarity of the drawing and the size of type used for call-outs may be just right for students up front but a blur for those in the rear. Finally, the instructor's description or explanation is usually given once, unless there are questions from someone in the class. The back-and-forth examination of figure and explanation in the text is not available to the student in the classroom. These differences should be kept in mind when selecting figures from printed sources. In fact, most figures found in books, manuals, and magazines are not appropriate for use, as is, but they can be changed or altered without too much difficulty. Most of this handbook is about how to do just that.

Illustrations can be found in a variety of formats. They vary from photographs to various kinds of drawings to schematic or symbolic representations. In general, photographs do not make good vugraphs, especially if they are copied from sources such as training manuals and books. What looks good on the printed page often does not copy or project well. Line drawings, either in perspective or as sectional views, and schematics fare better as vugraphs or slides. The many examples shown throughout the handbook will show you what to look for and some pitfalls to avoid in finding suitable illustrations. 


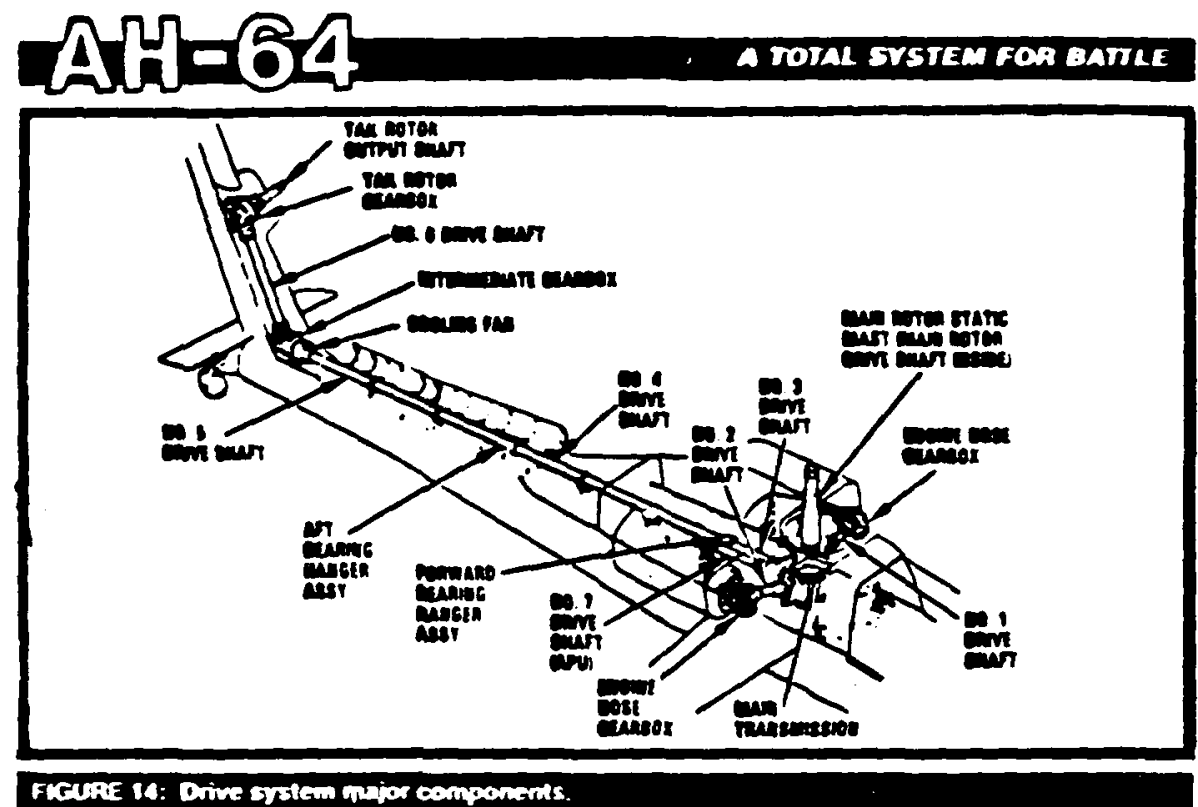

\section{Drive System Major Components}

The AH-64A helicopter uses ceved different components (figure 14) to transmit engine power to the min and tail rotors.

The main engines normally power the drive system through the nose searboxes, inpul shafts, couplings and input quill clutches 10 the main transmission. Through gearing, primary powertrain drive for the accessory rearbox (AGB) is from the No. 2 engise. The primary powertrain drive for the tail rotor is from the No. I engine.

When the main engines are shut down, the auxiliary power unit (APU) is used to provide power to the transmission AGB. The APU power drives the $A G B$, which in turn drives two ac generators, two hydraulic pumps and the shaft driven compressor. The auxiliary power unit does Dot drive the main or tail rotor asemblies.

The major components in the drive gystem are:

- number I Dose gearbox

- number I input shafí

- number two nose gentox

- mumber two input shaft
- aumber three drive shaft (forward shon shafi)

- number four drive shaft (forward long shaft)

- sumber five drive shaft (aft long shaft)

- number six drive shaft (uil rotor shaft)

- number ceven drive shaft (APU shaft)

- min drive shaft

- muin transmission

- intermediate searbox (IGB)

- ril rotor genrbax (or 90 degree)

- coline fan

- common couplinos

- dampers and antinail assem. blies

- forward and aft bearing hanger assemblies.

Each nose gearbox (figure is, page 28) is mounted to the encine main frame and coupled to the enpine by a houting type quill shaft. The nose gear box fairing esembly is beated to prevent the formation of ise around the fairing and the gearbox.

A cooling fan is bohed to the nose cearbox output shaft adapier and cooling fins extend into the coolins air stream to dissipate heat build-up. The impending bypass (pop-up) button on the filter and the nose geurbox oil kevel sight plus ore readily visible thride the fairing.

The transmission (figure 16, page 28) is driven by the muis engines through two overnunning type input clutches that permit engine decou. pling for aururotation or encine churdown.

The min transmission (firure 17 , page 28) provides the recessary change in direction of drive and reduces apeed to drive a primary and eccessory drive train. It is located bebw and atrached to the main rotor eupport structure. The transmission ecopers a rorque load only. This design feature allows a bighter then sormal transmincion to be used.

Lftins and bending moments are trensmitted from the min rotor. through the antic mant and suppor. ins structure, into the belicopter etencerure.

The trensmintion has a single senge planetary orrem with three anges of opeed reduction whin tes primery

Figure 1.0 Good Printed Material that makes a Poor Vugraph 


\section{RULES AND EXAMPLES}

Before we consider some rules for producing good vugraphs and slides, we must point out a drawback with this handbook. It is difficult, if not impossible, to reproduce in a book what the student will see on the screen in a classroom. The same problem faces anyone trying to select illustrations from books or manual for use in the classroom. A good practice, until you become familiar with the process, is to make a transparency and project it before you alter it according to the guidelines in the handbook. By providing "before" and "after" examples, we will try to point out what features of the book illustration have to be considered when projection is taken into account.

our first rule is:

RULE \# 1 REMOVE ALL UNNECESSARY MATERIAL FROM AROUND THE FIGURE.

This rule may seem obvious but it is often broken by those in a hurry to produce visual aids. Figure 2 is an example of a case where the training developer found a good illustration to use, Figure 2-63, Conversion of Torque to Work, but didn't bother to convert it into a good vugraph. All that is needed here is to make a copy of the page, cut out Figure 2-63, paste it on a clean sheet of paper, and make a transparency. Figure 3 shows the result of this simple, quick operation.

A note of caution is needed here about office copiers. As you may know, each time you copy anything, you lose some detail and the copier may introduce some "spots" of its own. A copy of a copy gets worse. If possible, you should cut out the original and use that to make the vugraph. If people object to you cutting up their TMs or magazines, then make a copy for your cut-and-paste effort.

There are good reasons for never violating this rule. Figure 2, the text and graphs distract the viewer from the smaller figure. The instructor must try to focus the attention of the students on just this part of the image on the screen. This is not always easy to do since the extraneous material may prove more attractive than the relevant figure. Figure 3 , on the other hand, removes everything but the figure and centers it in the middle of the vugraph. The extra few minutes it took are well worth the effort.

The examples which follow usually combine the application of several rules but we will hold our observations to just one or two with each one. Our next example reflects two more rules: 


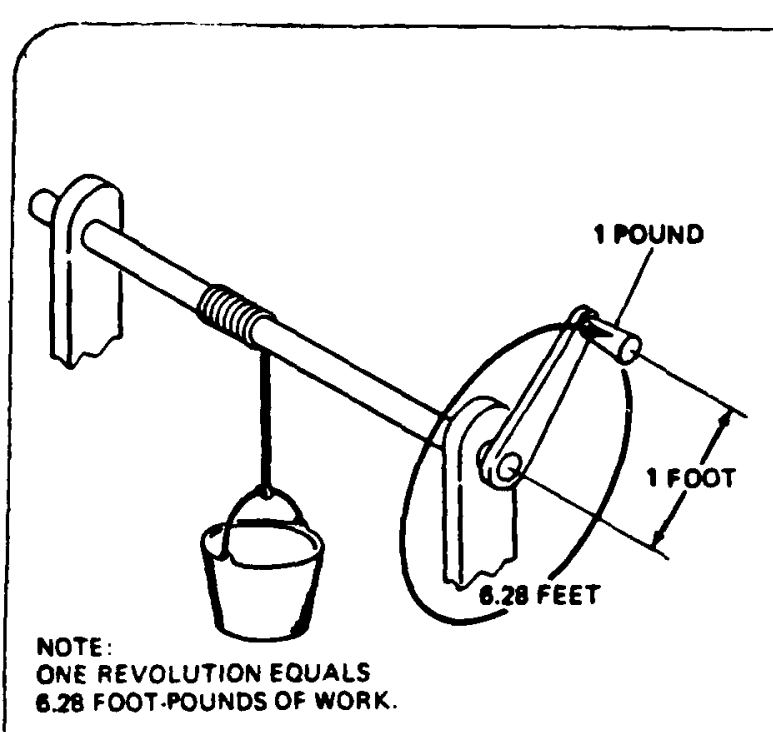

Figure 2-63. Conversion of Torque to Work.

b. Torque can be substituted into the formula because it is equal to the length of the arm times the scale reading. This yields:

\section{$6.28 \times$ torque $\times$ engine $\mathrm{ppm}$ 33,000}

c. This can be simplified further by dividing the 33,000 constant by the 6.28 constant. This provides a formula that shows a direct torquehorsepower-speed relationship:

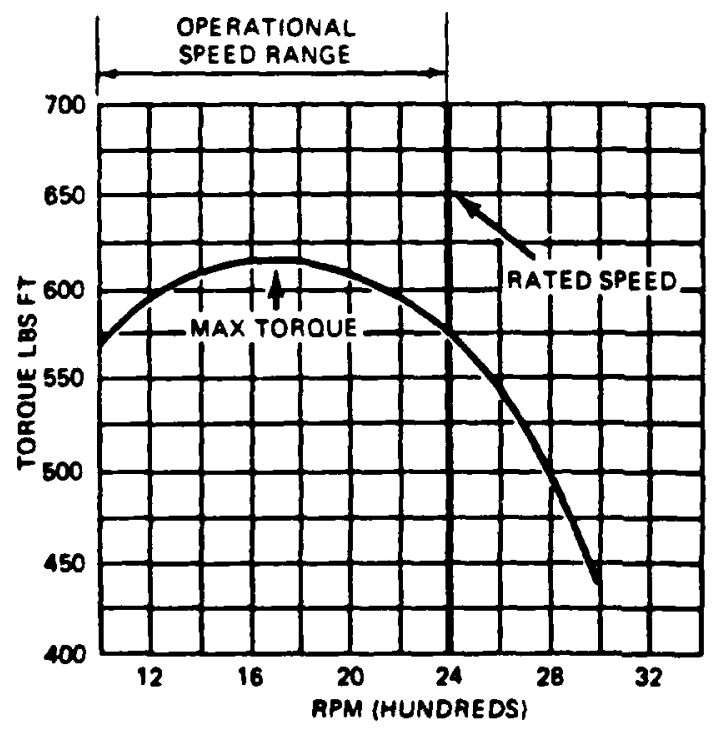

Figure 2-64. Torque Output Versus Speed.

$$
\text { Brakehorsepower }=\frac{\text { torque } \times \mathrm{rpm}}{5,254}
$$

2.34. Rated spoed. The rated speed as indicated in figure $\mathbf{2 . 6 5}$ is the speed at which the governor In a military vehicle is set. The rated speed usually is just under the maximum horsepower speed. Operation over the rated speed. causes disproportionate engine wear and excessive fuel consumption.

2.35. Cross and Not Horsepower. The gross horsepower of an engine is the amount of power the engine delivers without any accessories or a muffler. Net horsepower is the horsepower left to propel the automobile after the requirements of all of the accessories have been deducted from the gross horsepower.

2.36. Indicated Horsepower. Indicated horsepower is the power developed inside of the engine based on the pressure developed in the cylinders. It is always much higher than the brake horse. power because it does not consider friction or the inertia of the reciprocating masses within the engine.

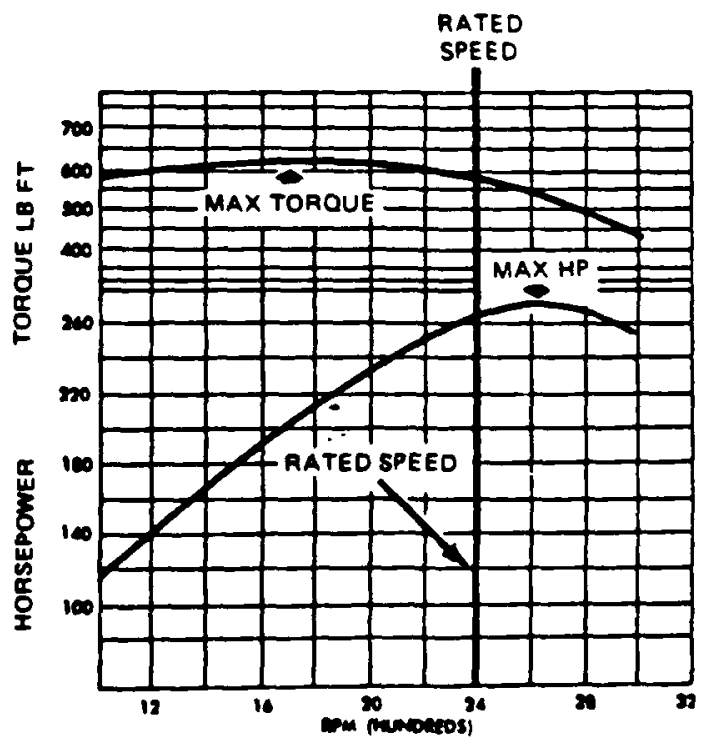

Figure 2-65. Torque-Horsepower-Speed Relationship.

Figure 2.0 Violation of Rule 1: Too Much Information Around the Graphic 


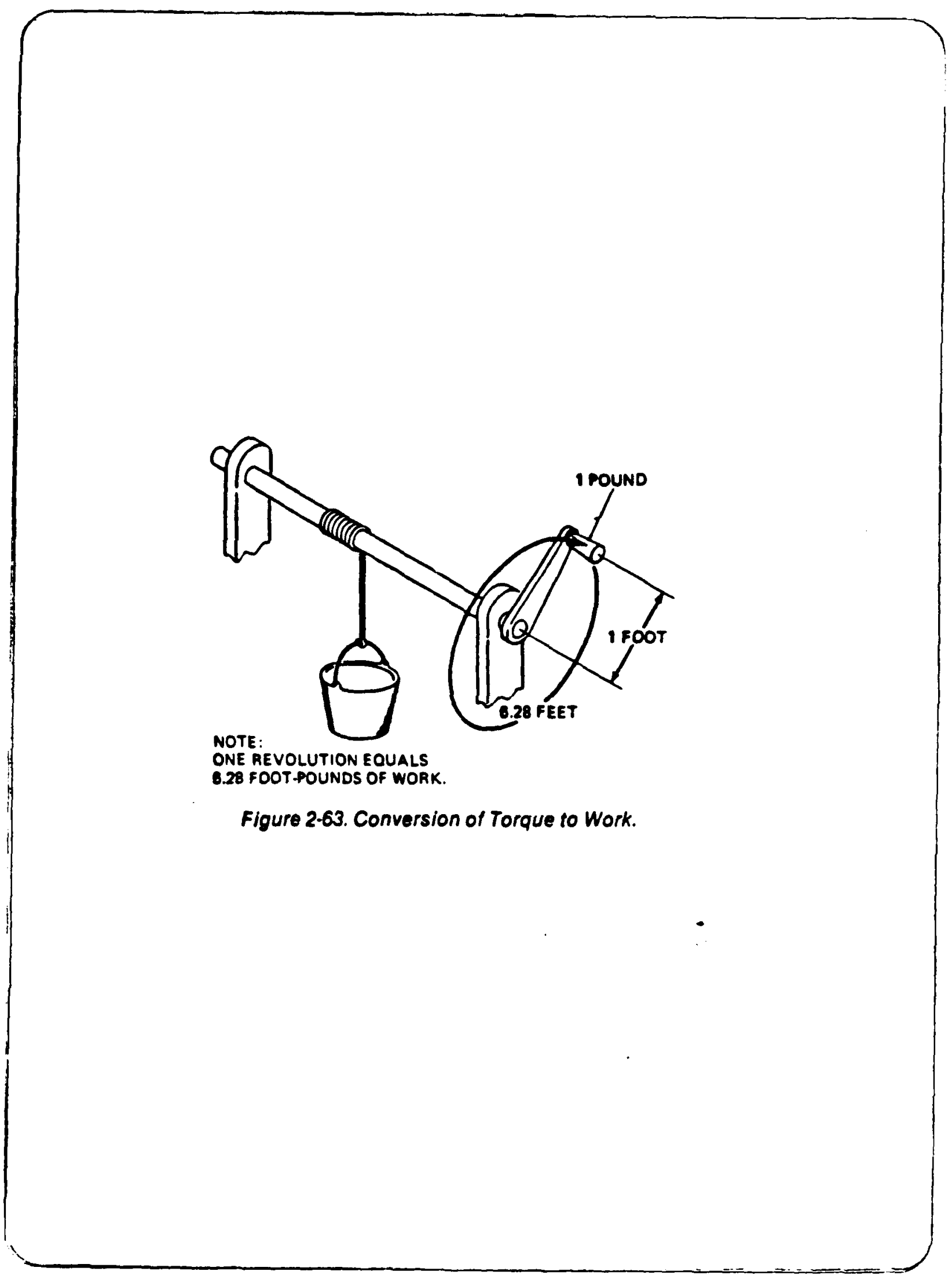

Figure 3.0 Application of Rule 1 
RULE \#2 MAKE FIGURE REFLECT MAIN TEACHING POINT

closely related to this rule is:

\section{RULE \#3 ELIMINATE UNNECESSARY DETAILS}

Our example for applying these rules comes from a course in automotive principles. The main teaching point, taken from the Lesson Plan, was to describe the cylinder block of an internal combustion encine. Figure 4 is the vugraph actually used to illustrate this point. The photograph chosen to show the cylinder block, although packed with information, has a number of drawbacks. For example, it doesn't project well on a screen and it shows a lot of parts associated with but not a basic part of the main teaching point, the cylinder block.

We looked for a better illustration and found one in the technical manual, TM 9-8000, Principles of Automotive Vehicles. Figure 5 is a vugraph we made by cutting out the figure from a copy, pasting in on a sheet of white paper, and making a transparency from it. Although this is a big improvement, we felt it could be made clearer. In Figure 6 , we eliminated the lower part of the figure, an upside down view of the crankcase because the crankcase is not part of the main teaching point. By cutting and pasting, we eliminated one of the call-outs (engine block) and moved one (water pump mounting) to the side, following some rules we introduce later. Finally, we used a white correction fluid to eliminate unnecessary detail like the small black dots representing bolt holes. The result is a clear, clean figure showing the basic details of a cylinder block.

The labels, or call-outs, within a graphic, should help the viewer and not get in the way, as they often do. Several rules pertain to these labels.

RULE \#4 REDUCE THE NUMBER OF CALL-OUTS TO FIVE OR LESS

This rule relates to Rules \#2 and \#3 which state that you should confine the graphic to the main teaching point and eliminate unnecessary details. The number five is somewhat arbitrary but emphasizes the need to reduce the amount of information in any one graphic to a manageable level. Another aid in simplifying graphics is found in the next rule.

\section{RULE \#5 LINE UP THE CALL-OUTS}

By this rule, we mean to position the call-outs so they are nearly the same distance from the picture. The arrow or pointer from a call-out to the figure should be nearly vertical or horizontal. What this does is to more clearly identify the call-outs as labels leading to the part to be identified instead of being part of the picture. The next example shows how these 


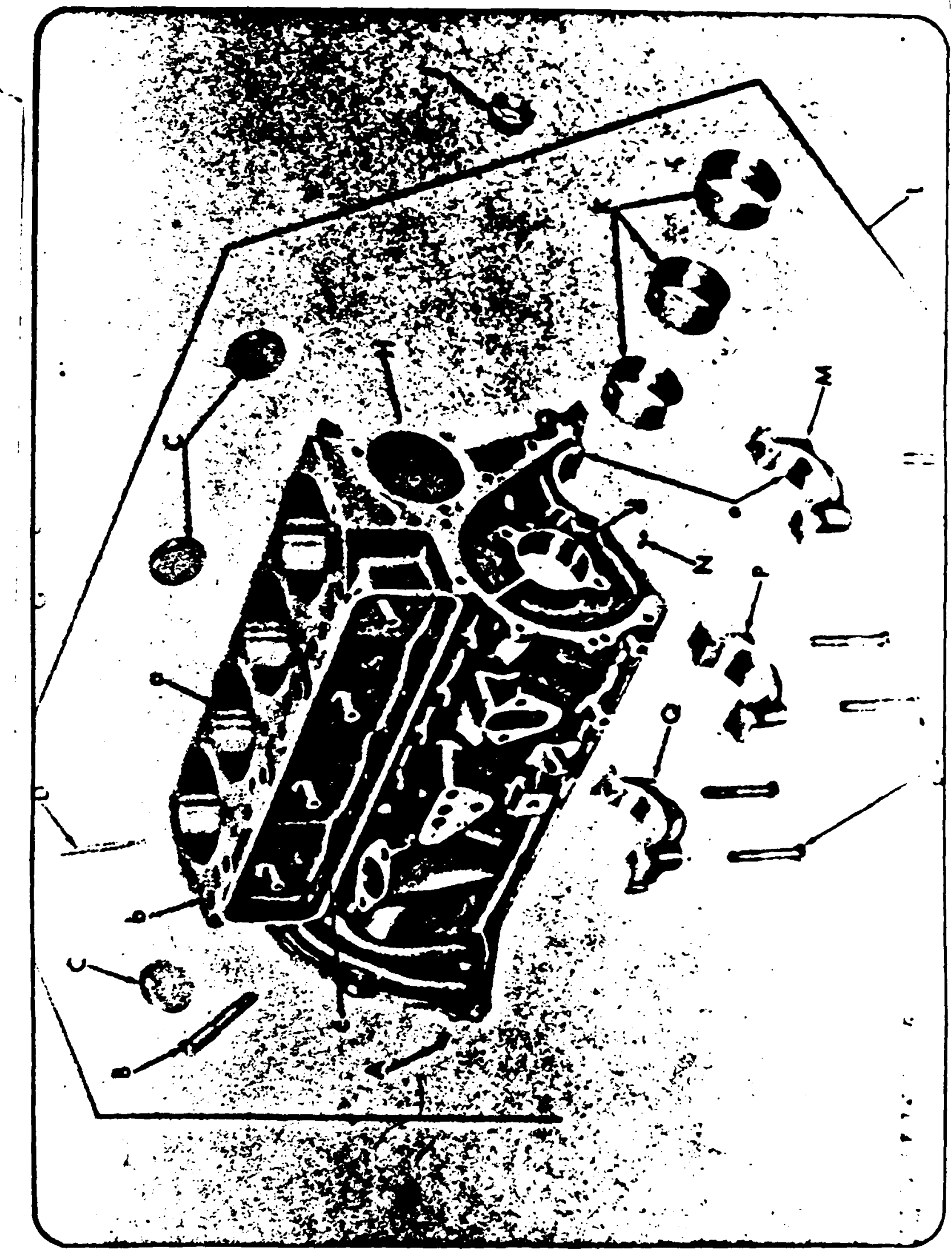

Figure 4.0 Teaching Point clear (Rule 2) But Too Much Information 

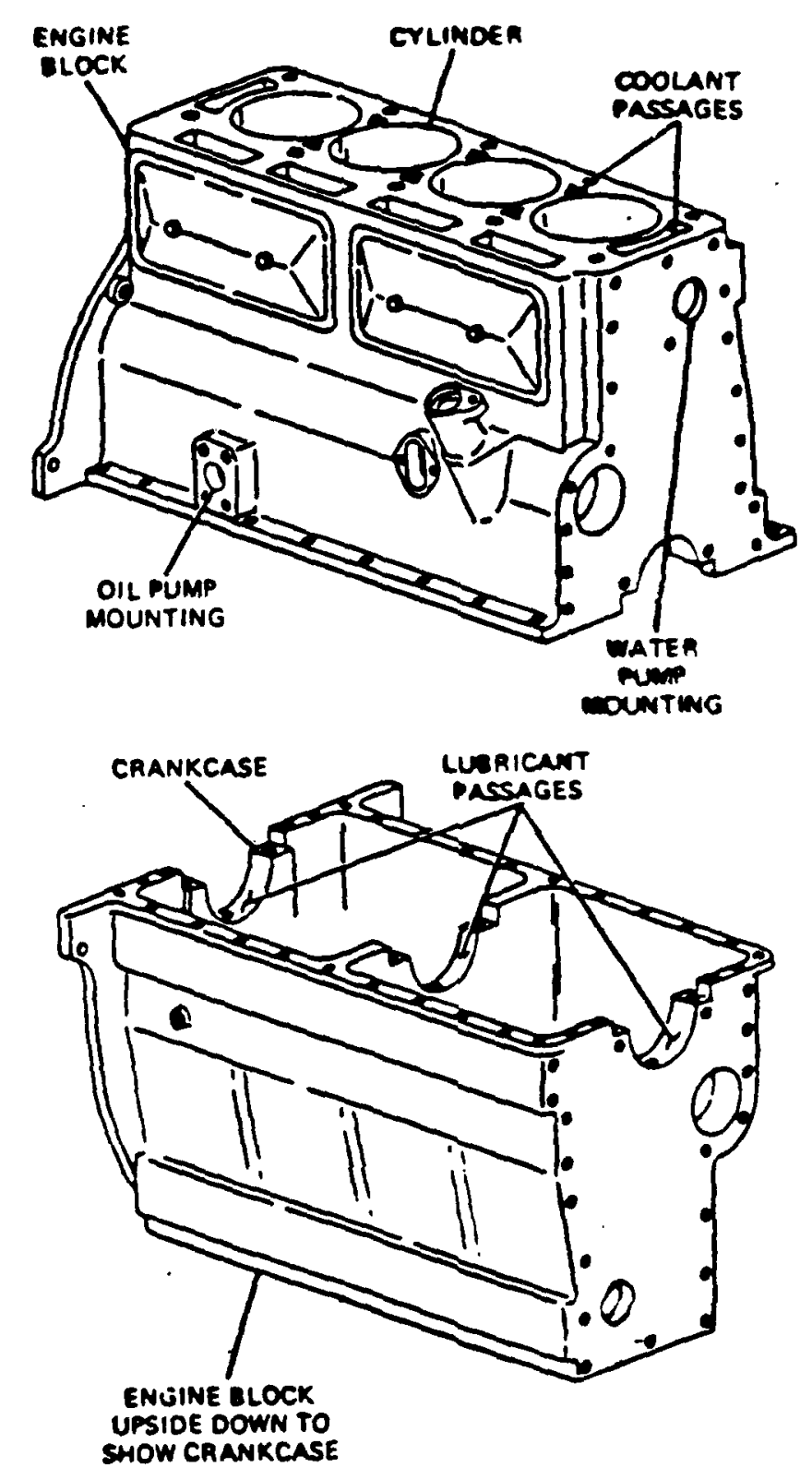

Figure 3-1. Lquid-Cooled Cylinder Block.

Figure 5.0 Teaching Point Clear, But Still Too Much Information 


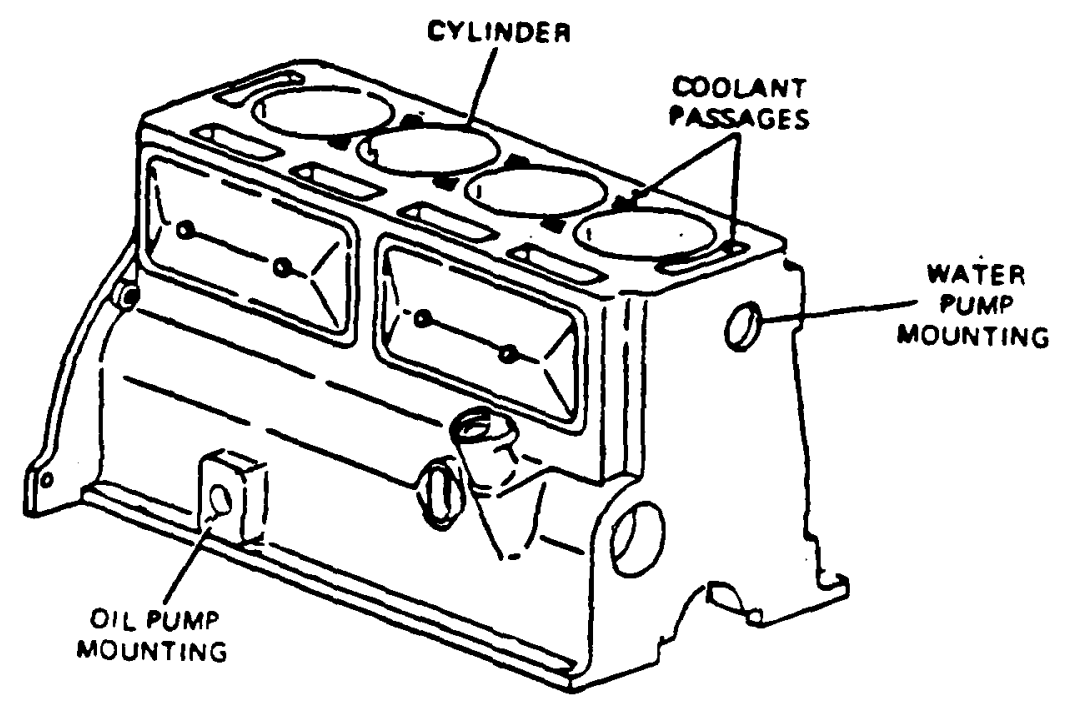

Liquid-Cooled Cylinder Block.

Figure 6.0 Teaching Point Clear, Unneeded Information Cut 
rules may be applied. Figure 7 is an original vugraph that was used to illustrate an automotive crankshaft. This graphic also includes numerous other internal engine parts with a total of 27 call-outs scattered all over the graphic. The graphic certainly violates most of the rules we've introduced so far. Figure 8 is taken from TM 9-8000 and neatly and clearly summarizes the main features of a crankshaft. The unnecessary detail found in Fig. 7 has been eliminated, the number of call-outs has been reduced to five, but the call-outs are too close to the figure. In Figure 9, by cutting and pasting, we moved the call-outs away from the figure and, generally, lined them up. Notice too that we eliminated the figure number from the manual illustration leaving a clear title for the graphic. graphic.

There is a final rule for call-outs in making a good

\section{RULE \#6 MAKE CALL-OUTS CUE MORDS, NOT SENTENCES OR EXPLANATIONS}

It is common, in books and manuals, to do more than merely label things in an illustration. The viewer in a classroom, however, doesn't have time to read an explanation or long sentences. That is the function of the instructor. The following examples shows this practice and what you can do to remedy it. Figure 10 was taken from TM 9-8000. It illustrates and explains the function of the crankshaft counterweight all within the confines of the figure. Following Rule \#6, we made Figure 11 by simply labelling the parts and, following Rule \#5, lining up the call-outs to the side. The lengthy explanation of the need for counterweights in the original figure has been eliminated, to be supplied by the instructor using the graphic. By the way, using only an office copier, scissors and paste, changing the original figure took no more than 15 minutes.

In the examples you have seen so far, one feature may have been evident; photographs tend to make poor graphics. In fact, we even have a rule:

\section{RULE \#7 AVOID USING PHOTOGRAPHS}

Most photographs available to you in books, magazines and manuals are realistic but have more detail than is necessary and often do not copy well as vugraphs. Because of their greater fidelity, they may be useful in showing what objects actually look like. For that reason, they usually fare better as $35 \mathrm{~mm}$ slides which use a sharper projection system than most overhead projectors. Our next example shows application of this rule, along with Rule \#6 about avoiding explanations as call-outs. Figure 12 was used to illustrate engine timing gears and $t$ ie timing marks associated with them (the main teaching point). We found a line drawing in TM 9-8000 (Figure 13) which improved on the clarity of the photograph used for Figure 12 but we didn't 


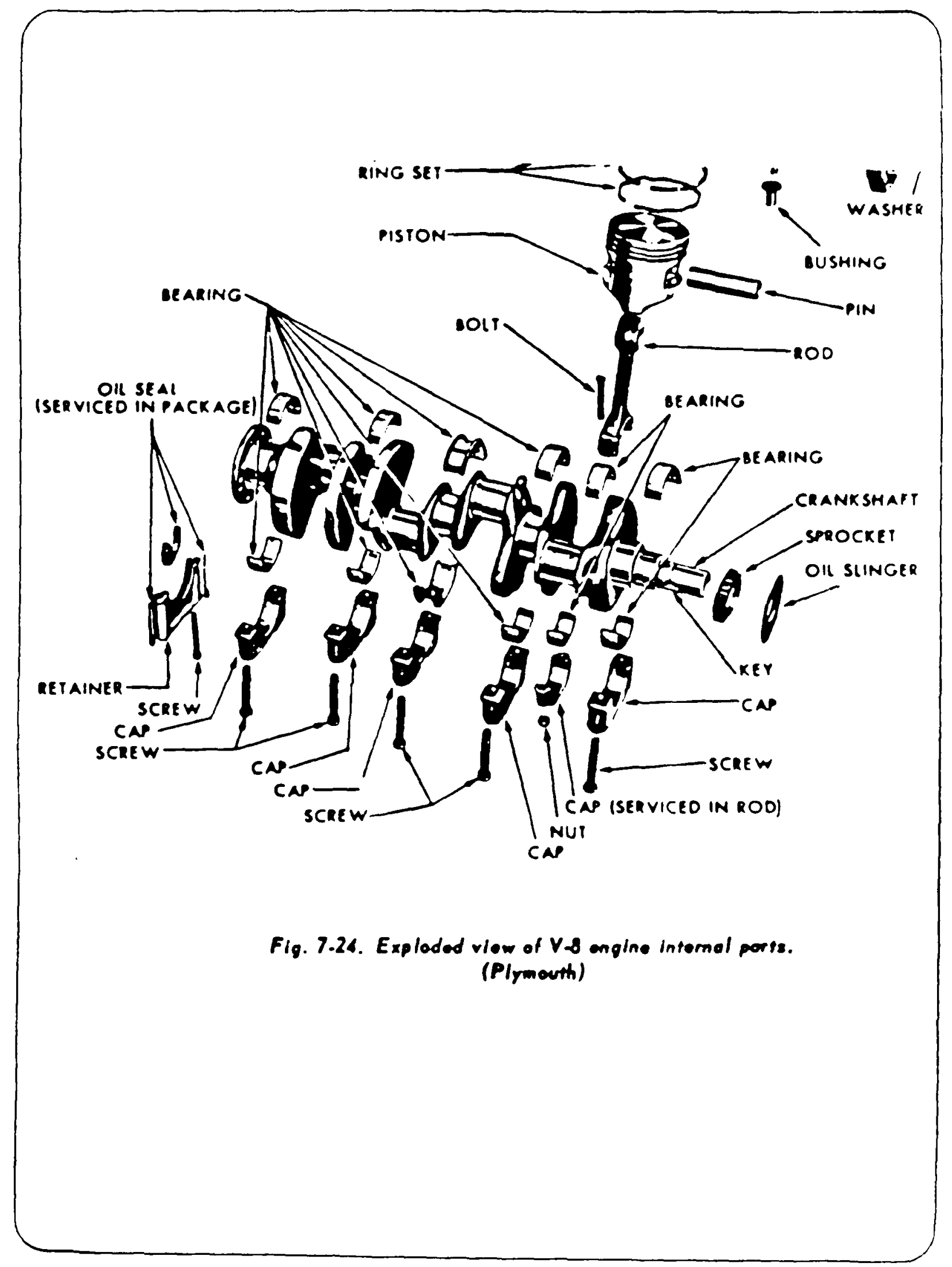

Figure 7.0 Too Many Cal1-Outs, Poorly Arranged 


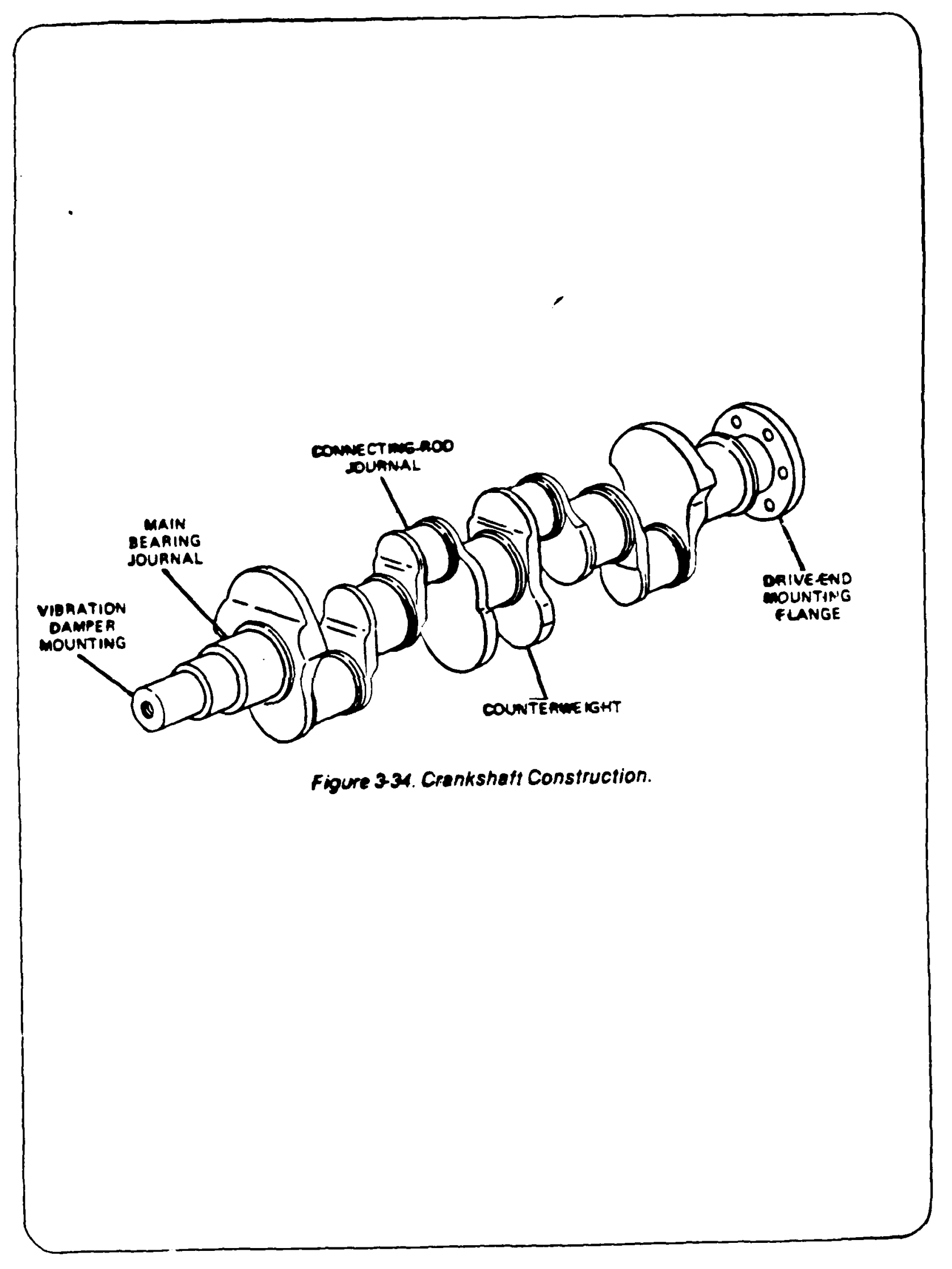

Eigure 8.0 Correct Number of Call-outs, Rut Still Poorly Arranged 


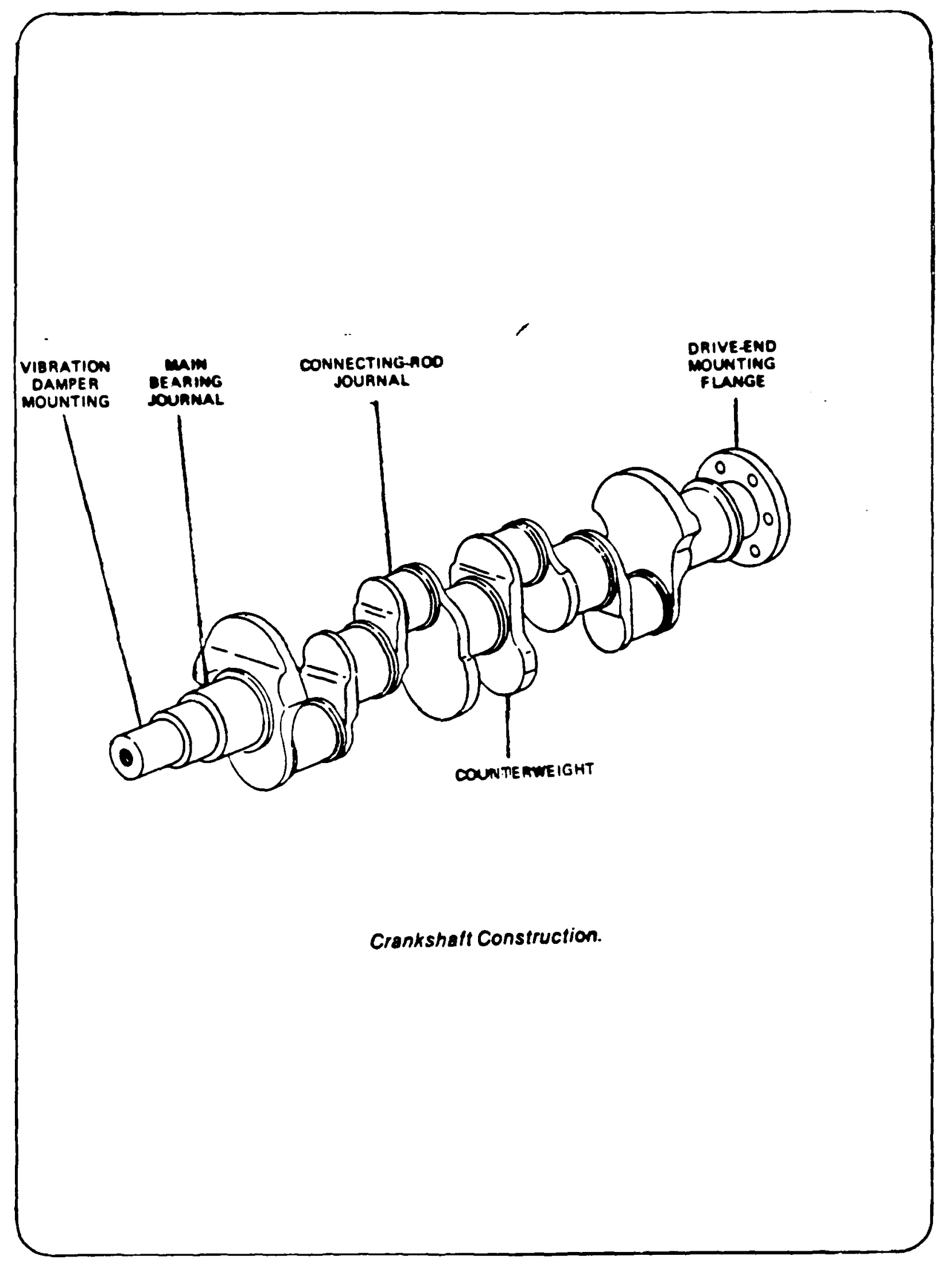

Figure 9.0 Correct Number of Call-outs, Properly Arranged 
COUNTEAWEIGHTS COUNTERBALANCE THE

IMBALANCE CAUSED BY

WEIGHT OF PISTON.

CONNECTING ROD

ASSE MBLY

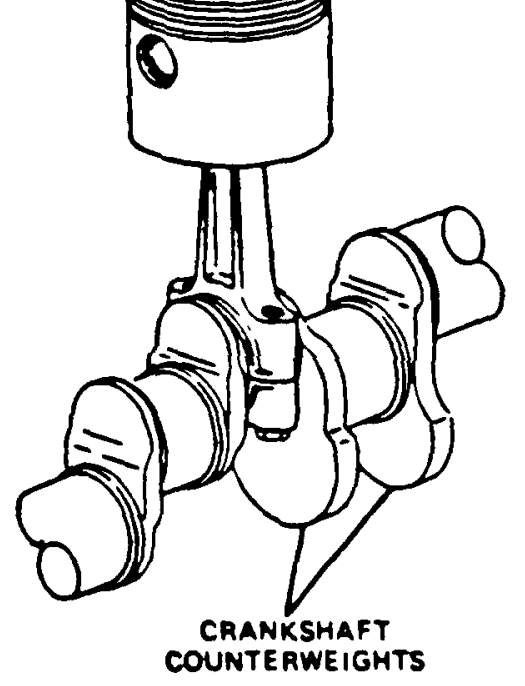

Figure 3.36. Crankshatt Counterweights.

Figure 10.0 Too Much Explanation 


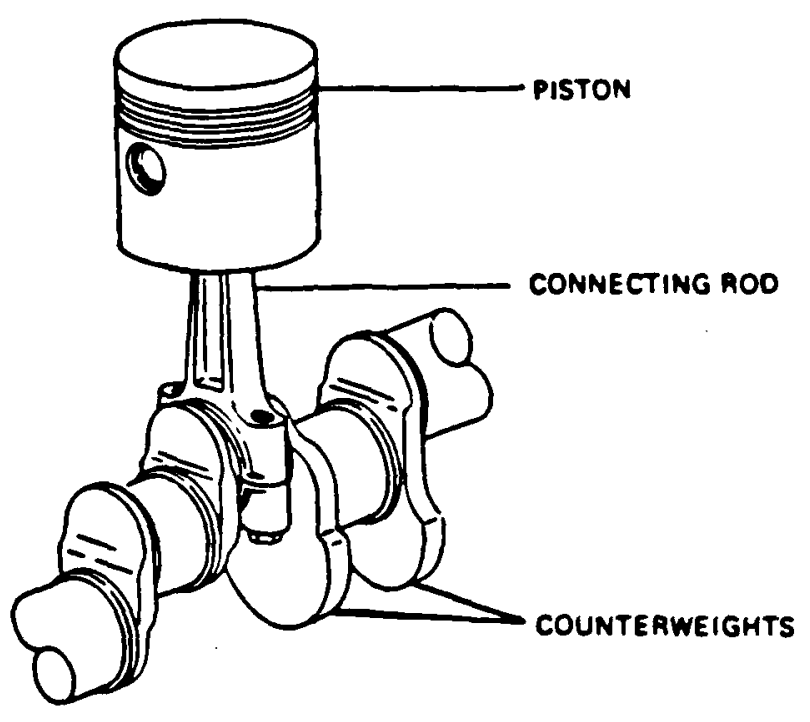

Crankshatt Countenweights.

Figure 11.0 Lengthy Explanation Cut 


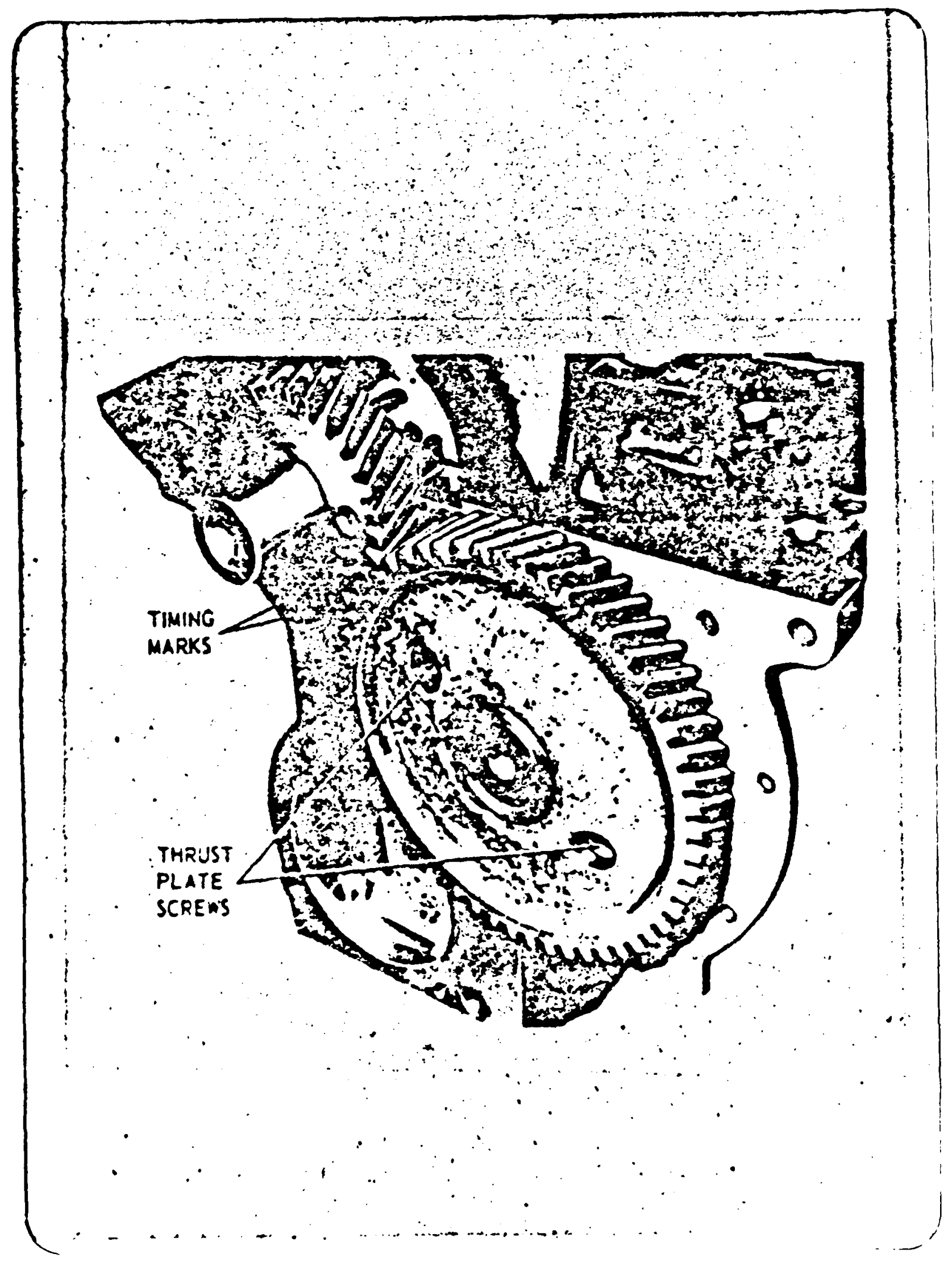

Figure 12.0 Example of Poor Use of Piotograpis: 


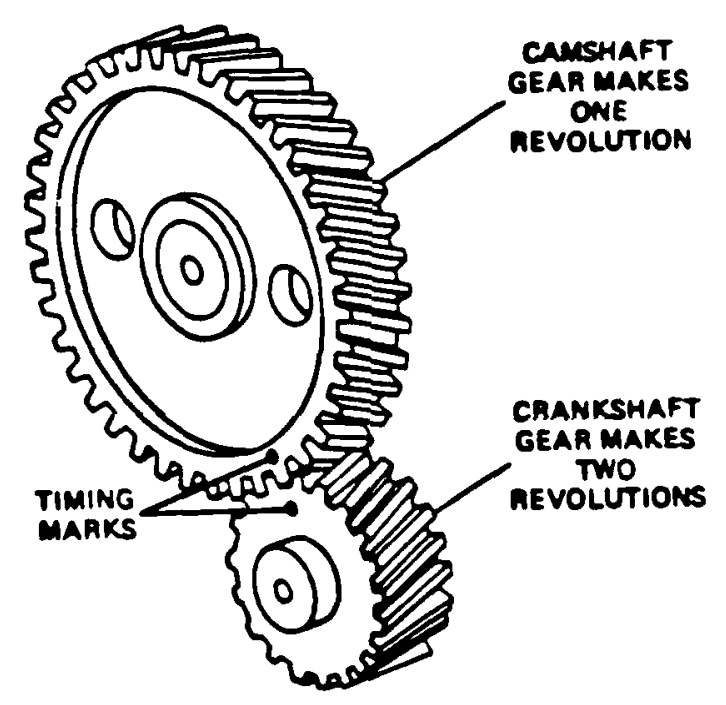

Figure 2-10. Timing Gears.

Figure 13.0 Drawing As Replacement for Photograph 
like the explanations used as labels. Using just the cut-and-paste method, Figure 14 shows our final product with the call-outs now labels and moved to the same side. It would be left up to the instructor to explain the gear ratio and its purpose to the students.

The layout or composition of a figure often causes problems for the viewer in a classroom. The student expects to see a fairly realistic portrayal of objects and doesn't have time to mentally turn things around the way one can with a figure in a book. Our next rule concerns the practice of some illustrators to turn things around or even upside down.

\section{RULE \#8 MAINTAIN A CORRECT SPATIAL ORIENTATION}

A couple of examples will show you what we mean by this rule. We are concerned with making sure that pictures are consistent within a graphic, as in the first example, and are consistent with the real world, as in the second example.

The first example, shown in Figure 15, was taken from TM 9-8000 and shows three different types of vibration dampers that might be found on the front end of an engine crankshaft. For some reason, the artist showed a stylized crankshaft on the left of the picture with the front end oriented towards the right. Each of the damper types, however, has been turned around so the front end of the crankshaft would be oriented towards the left. To make our vugraph, we decided to re-orient the dampers and to clean up the various labels, some of which violate Rule \#6 about using explanations as labels. Figure 16 is our finished cut-and-paste product. The dampers now maintain the proper spatial orientation to the crankshaft, the call-outs are now proper labels for the parts, and the whole graphic is easier to grasp as a whole. Notice that we used the printed words already in the original to form the call-outs.

Our next example illustrates application of Rule \#8 in the sense of picturing the world as it really is. The teaching point involved was the location of the oil pan on an automotive engine. The original vugraph is shown in Figure 17 which, by the way, is a very good exploded view of certain engine parts and does show the location of the oil pan. As a vugraph, however, it violates a number of our other rules. We located an illustration in TM 9-8000, shown in Figure 18, that showed the location of the oil pan and had very little additional detail but, unfortunately, was upside down. By turning that figure right side up, relocating two of call-outs, and eliminating the gasket (using correction fluid), we arrived at our final product, shown in Figure 19.

By this time, you have probably a pretty good idea about the message of this handbook. It is application of the old KISS (Keep It simple soldier) approach but we don't mean to be 


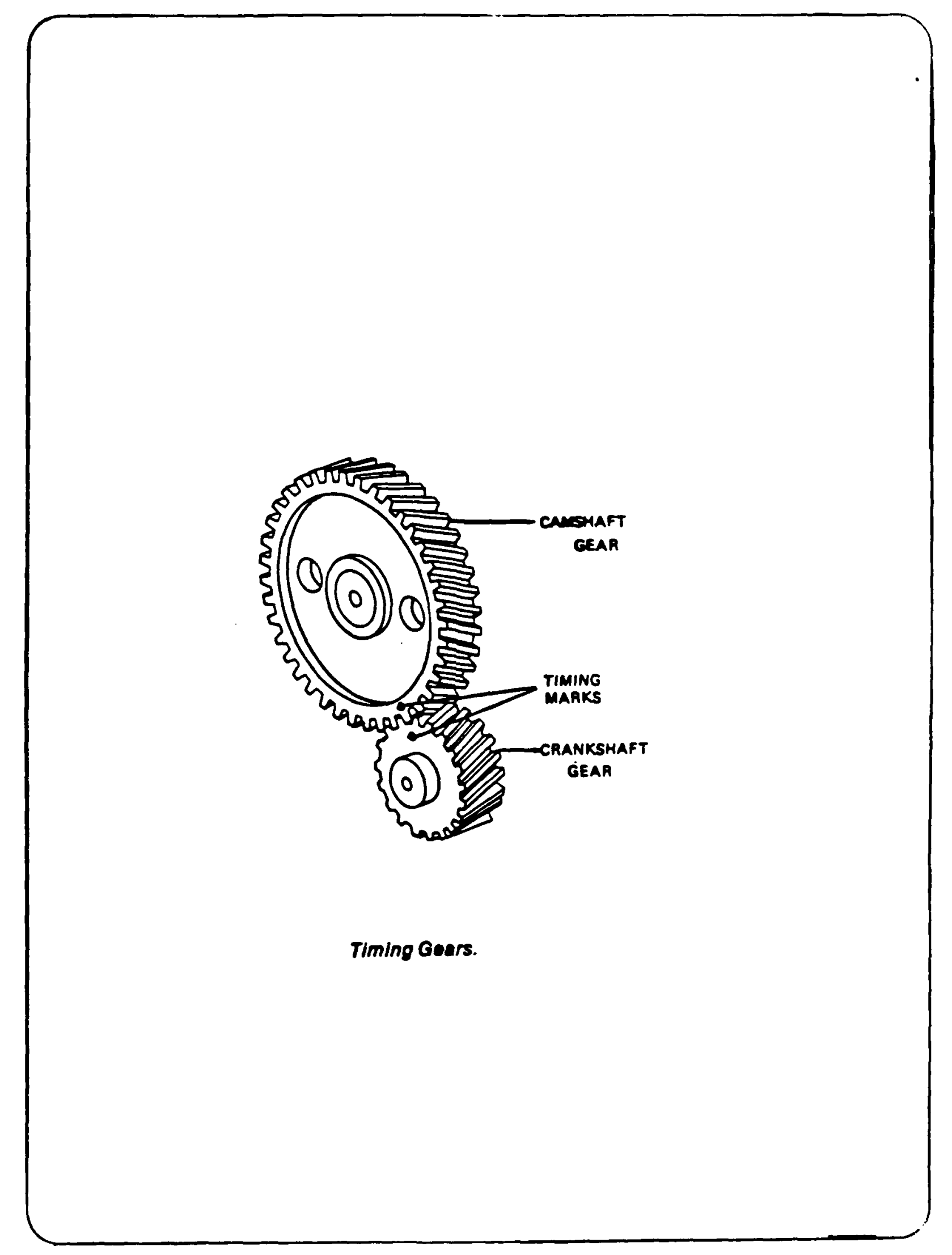

Figure 14.0 Improved Drawing As Replacement for Photograph 


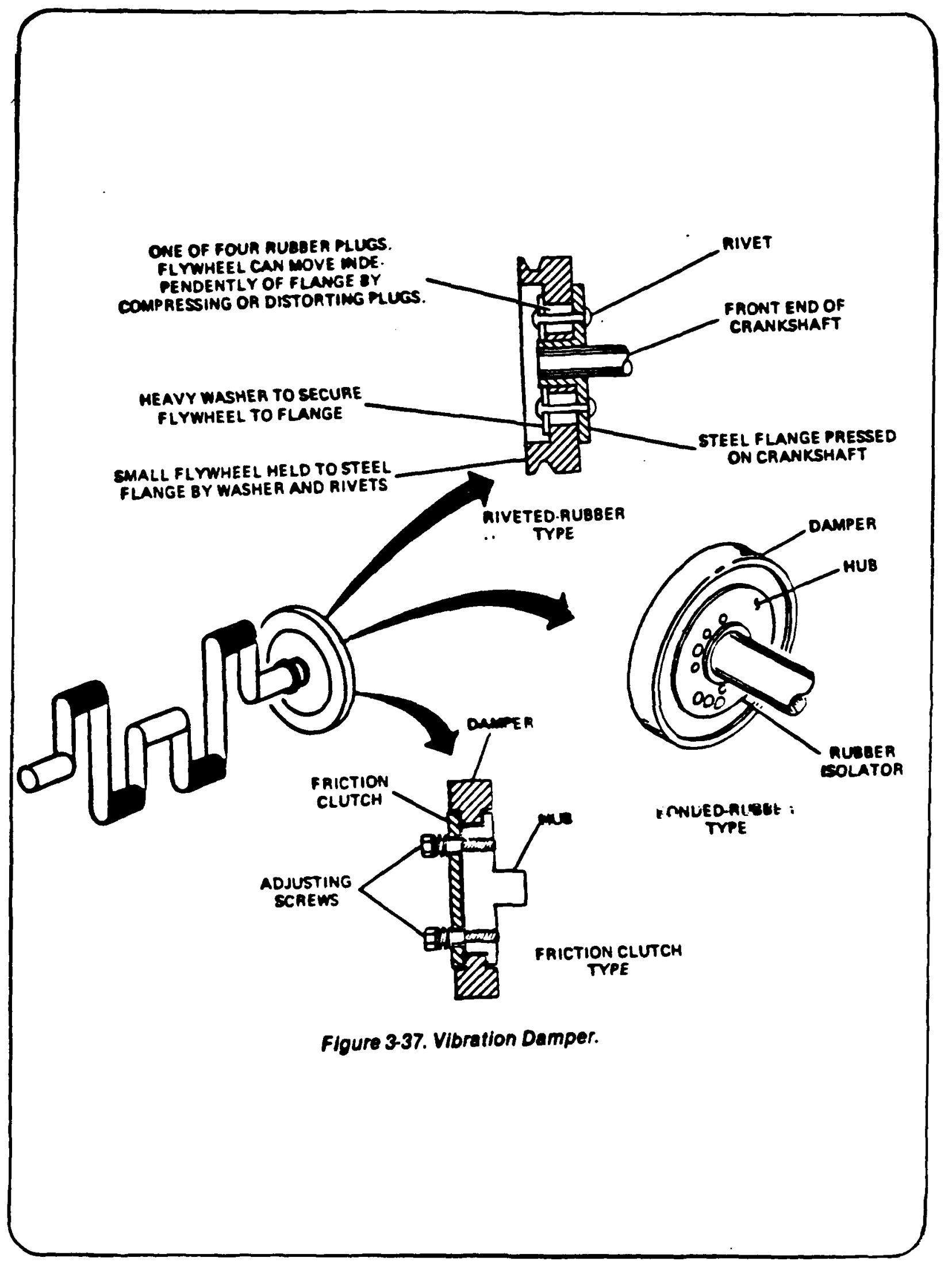

Figure 15.0 Incorrect Spatial Orientation 


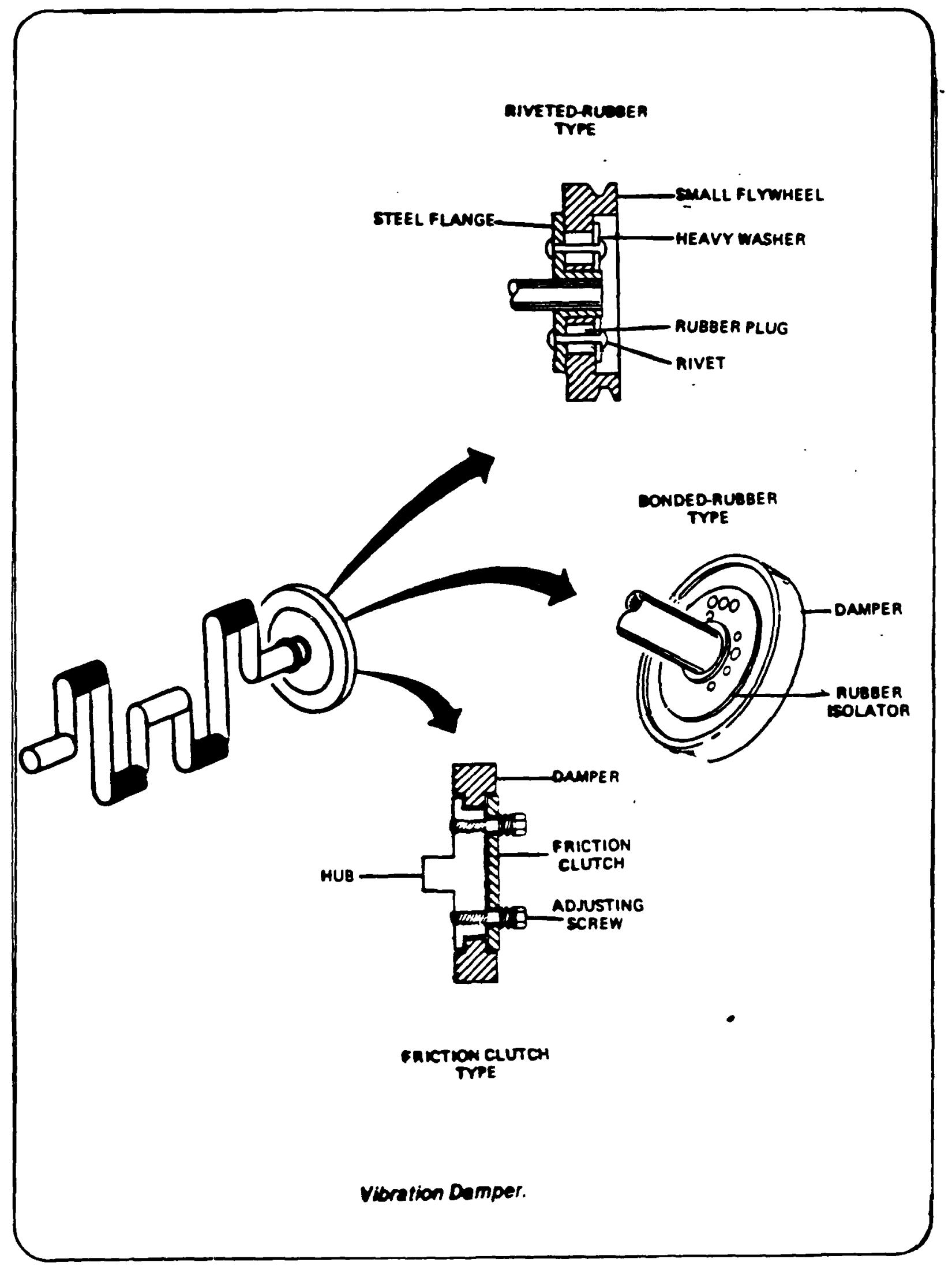

Figure 16.0 Correct Spatial Orientation 


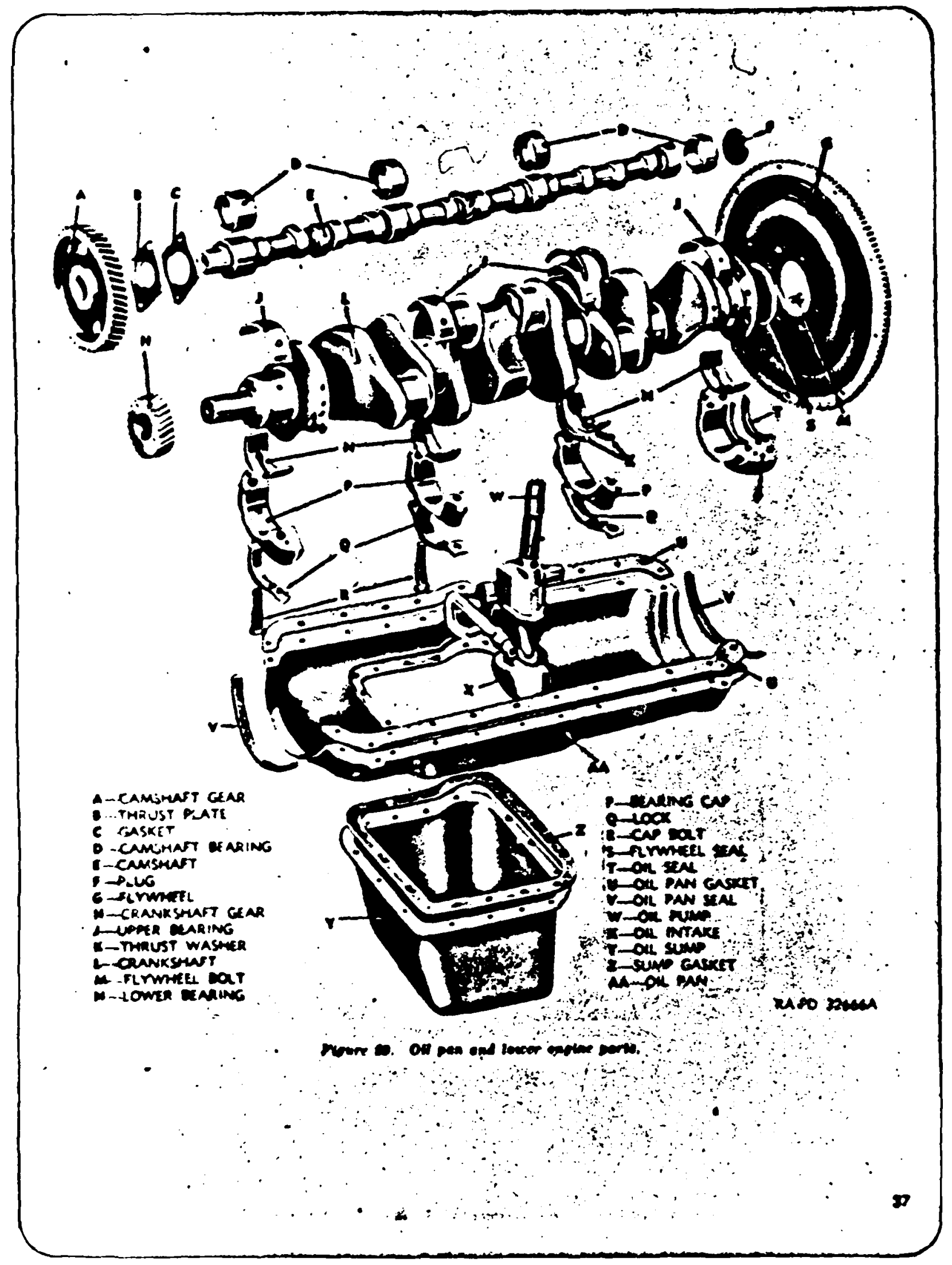

Figare 17.0 Good Spatial Orientation But Other Rules liolated 


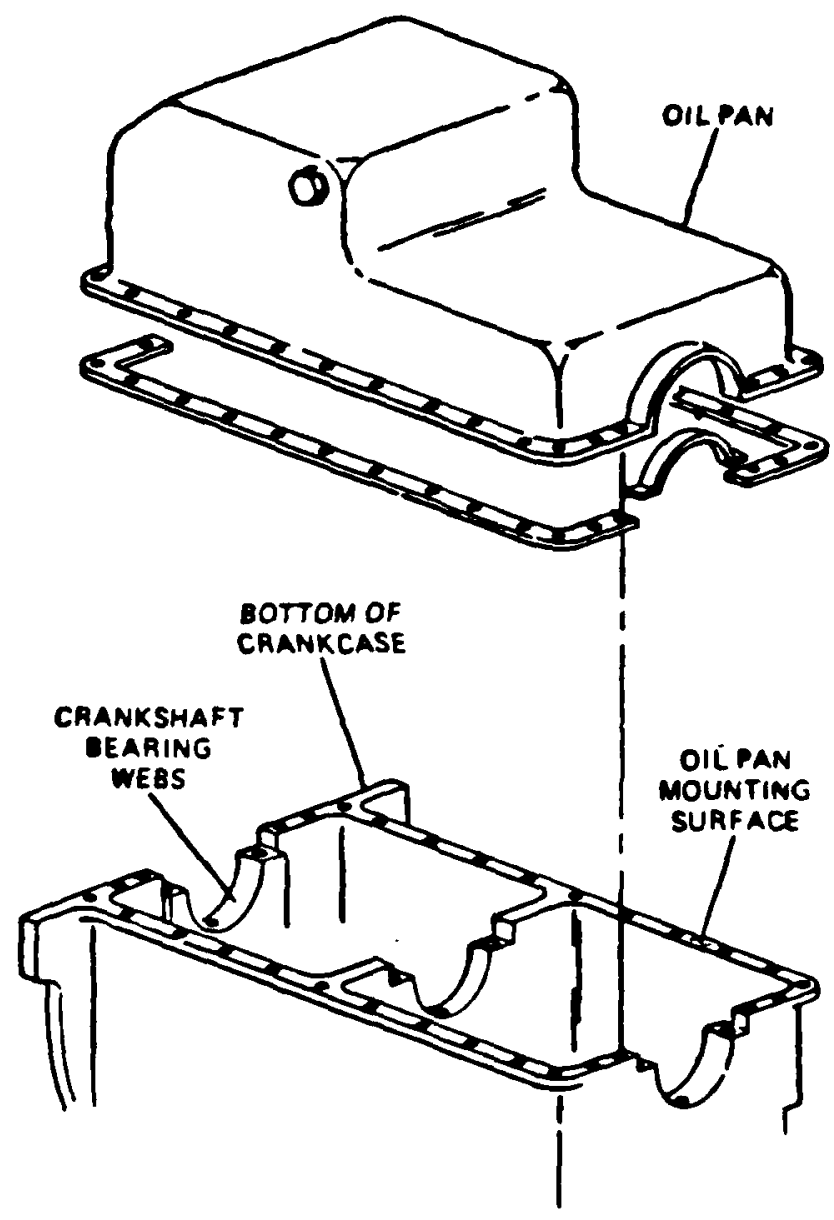

Figure 34. Engine Crankcase.

Figure 18.0 Clear Graphic, But Wrong Spatial Orientation 

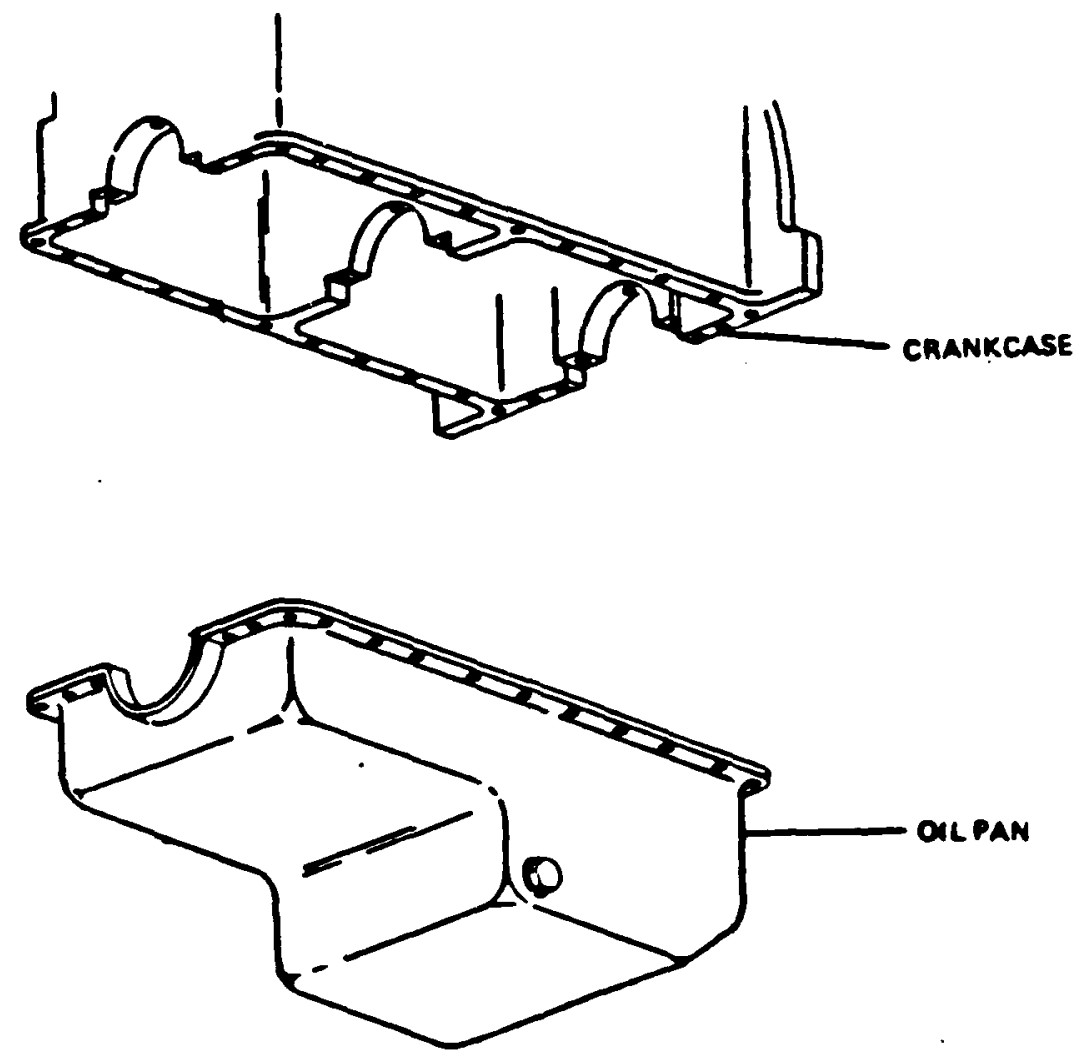

Engine Crankcase.

Figure 19.0 Clear Graphic, Good Spatial Orientation 
sarcastic. You can teach some pretty difficult concepts using that approach. What we are trying to do is to help everyone in the classroom by making clear and straightforward visual aids. If we can produce clean, simple and readable vugraphs and slides, the instructor can spend more time lecturing and answering questions instead of trying to explain confusing visual aids.

The rules we have presented so far cover the major considerations in converting book and manual figures into acceptable vugraphs and slides. There are two additioral rules that are more general than the others and, although they are presented last, they should be kept in mind at all times.

\section{RULE \#9 CHECK FOR ACCURACY}

You would think that your source material, books, magazines and manuals would be correct but, even so, errors do creep in. Sometines things are mislabelled or the pointers from call-outs are wrong. In altering figures, you may make mistakes. For example, if you are rearranging call-outs and have to redraw the pointers, make sure you do it correctly.

Here is an example of the "book" being wrong. Maybe you noticed that when we altered Figure 18 to make Figure 19 we changed one of the call-outs, the one referring to the "bottom of crankcase." Figure 20 shows you what the drawing looked like before we noticed the error. But, as TM 9-8000 points out ( $p$. $3-2)$, the oil pan is actually the bottom of the crankcase! In Figure 19, we corrected this error so the call-out simply refers to the "crankcase." A minor point, perhaps, but it is worth the effort to be accurate.

our last rule is one you should never break. It is especially important for those of you who are just getting started.

\section{RULE \#10 TEST VISUAL AID IN THE CLASSROOM}

What looks good on the worktable or desk in front of you may not when projected on a screen in the classroom. In this handbook, for example, it is difficult to recreate on the printed page what a vugraph looks like to someone in the classroom. Printed words, such as those in the call-outs, may be quite legible to you on the transparency, and even look ok at the front of the class, but leave you squinting in the last row. Details in drawings and figures may suffer the same fate. It takes some experience to be able to judge whether a book illustration will make a legible transparency or slide. With vugraphs, it is a good idea to make a test copy and project it before altering it according to our rules. Shortly, we will show you some tips for enhancing illustrations and correcting some of the deficiencies you discover by projecting the image. 

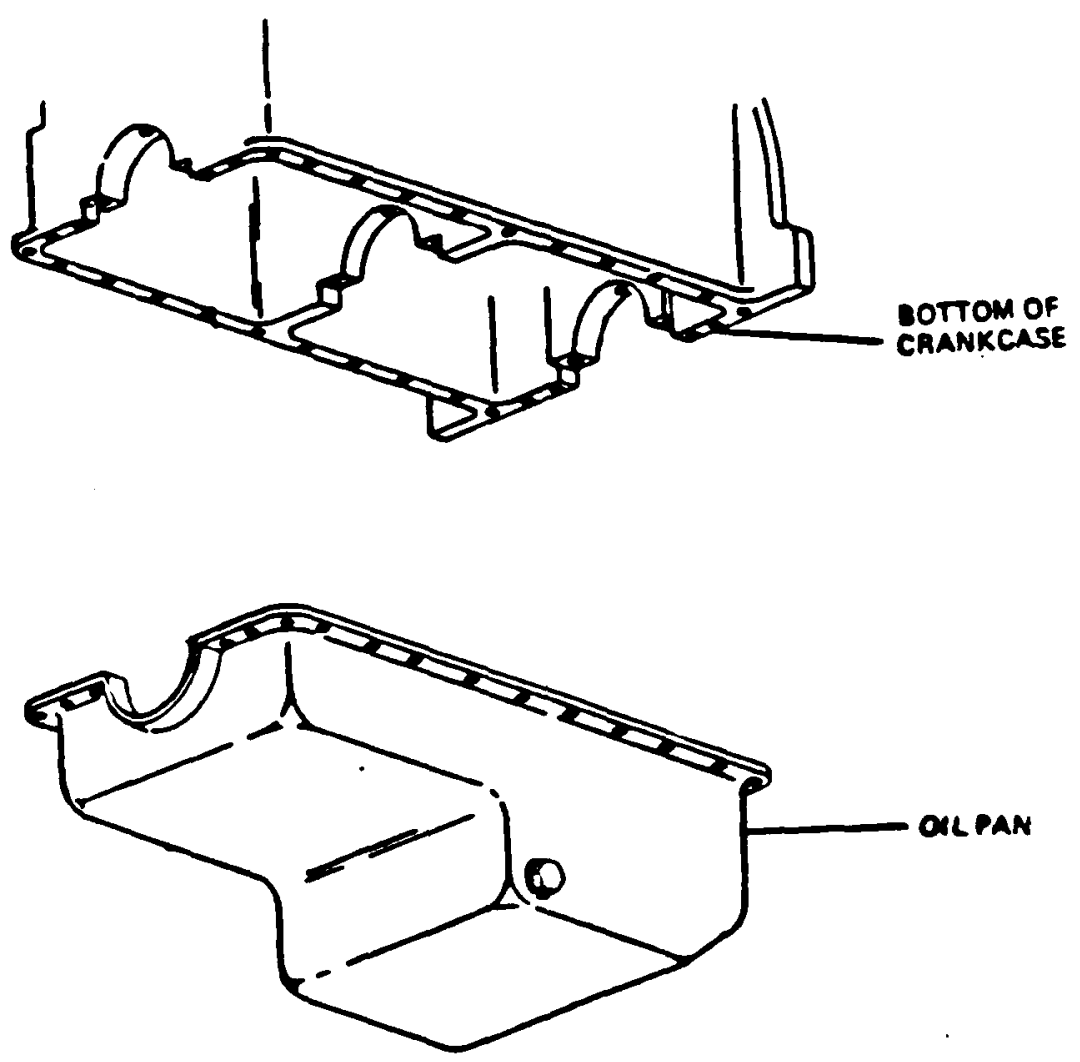

Engine Crankcase.

Figure 20.0 Clear Graphic, Good Spatial Orientation, Misinformation 
The object of this handbook is to help you produce clear and legible visual aids with a minimum of pain and strain. The examples we have shown so far have been produced with simple cut-and-paste techniques and require only an office copier and some transparency films. In this section we are going to show you some additional ways to improve the quality of visual aids.

Highlighting

Most of our examples have used Iine drawings which have the advantage of showing up clearly when projected. Sometimes, however, they can play tricks with your eyes. For example, we wanted to use the illustration shown in Figure 21 to show how piston rings are arranged in various engines. There are a couple of problems with the original drawing. First, you had to figure out which are the compression rings and which are the oil control rings since they aren't labelled in the figure. Second, we had trouble making out the rings what with all the curved lines. The first step was to rearrange the three pistons so they appeared vertically instead of across the page. This allowed us to use call-outs and pointers on the side of the figures to identify the two type of rings. After our cut-and-paste job, we used a regular lead pencil to shade in the background between the piston rings to make them stand out from the piston. When we made a transparency, following Rule 10, we found that our shading was uneven and too light, so we merely darkened it on our original and tried again. Figure 22 shows the results of our effort. As you can see, no great artistic talent was required nor is the result great art, but the new figure is better laid out and the shading lets us see the piston rings more clearly.

\section{Color}

Most copying machines available in Army schools are restricted to black and white but t-at doesn't mean you can't use color (even though we can't demonstrate it with color in the handbook). Our use of color is really a form of highlighting and requires, besides the usual scissors, paste and correction fluid, some color marker pens made for writing on transparencies. They are easily obtained and do not readily come off.

For our example, we chose a cross-sectional view of a part of an engine showing how the port leading to a valve had been redesigned to improve the flow of gases. The artist had used dotted lines to show areas where excess metal had been eliminated but this did not show up well on the transparency. Figure 23 shows the original illustration from the manual. We altered the title of the figure slightly and made a transparency. $T$.en, on 


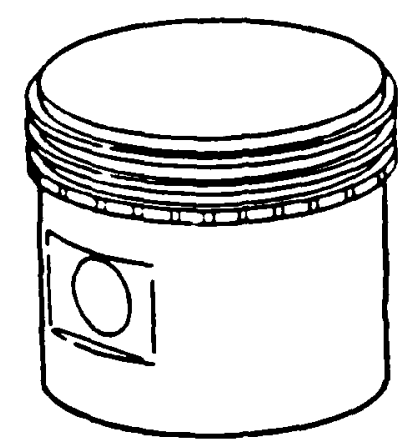

A. TMREE RING

TWO COMPRESSION RMES ONE OIL CONTROL RING

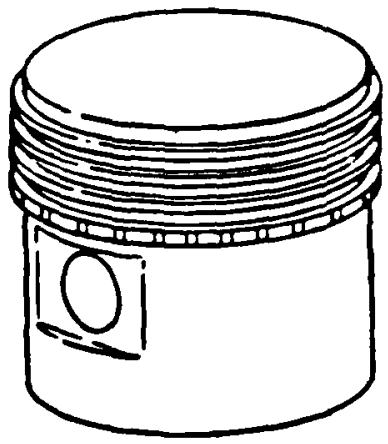

B. FOUR aing

THREE COMPAESSION RINGS ONE OIL CONTROL RING

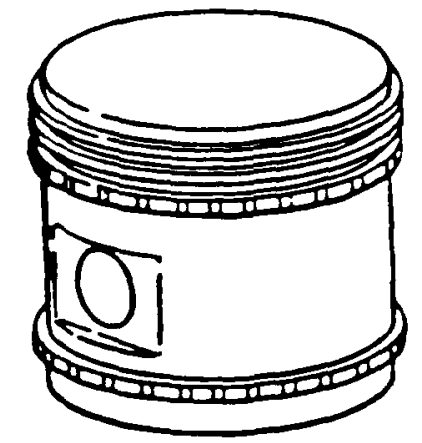

c. FOUR RING

nWo compaession AINGS TWO OIL CONTAOL RINGS

Figure 319. Configurations of Piston Rings.

Figure 21.0 Need for Highlighting 


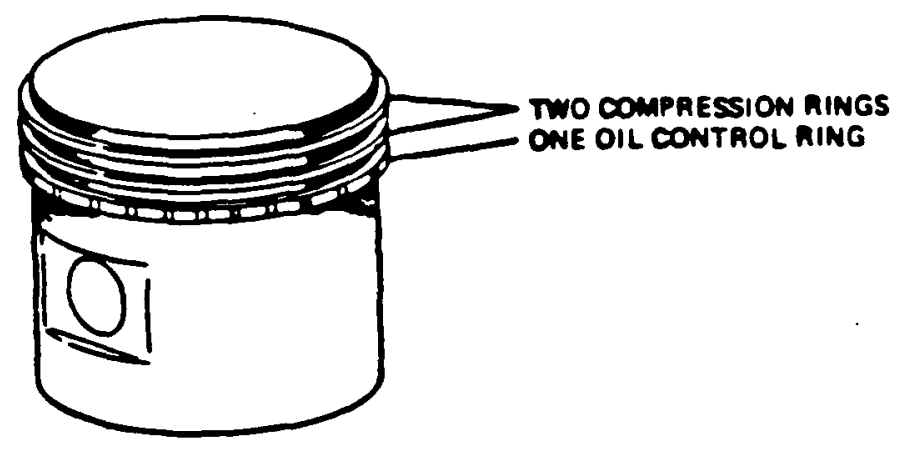

A. TMREE RING

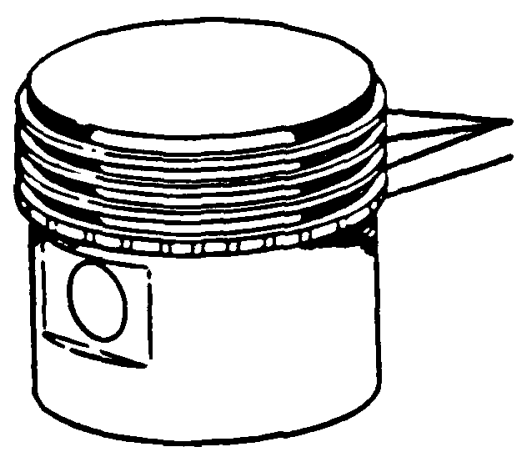

thaEe COMPRESSION RINGS ONE OIL CONTAOL RING

- four Ring

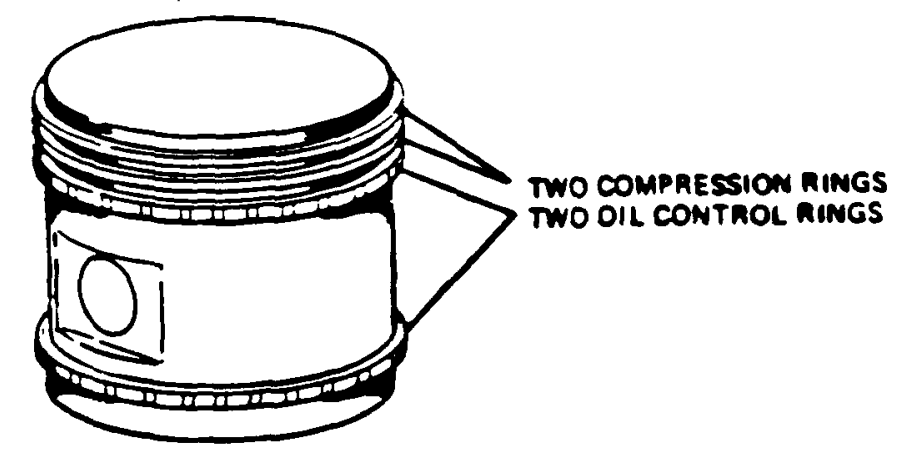

C. Foun RING

Configurations of piwen fings.

Figure 22.0 Use of Highlighting to Bring Out Details 


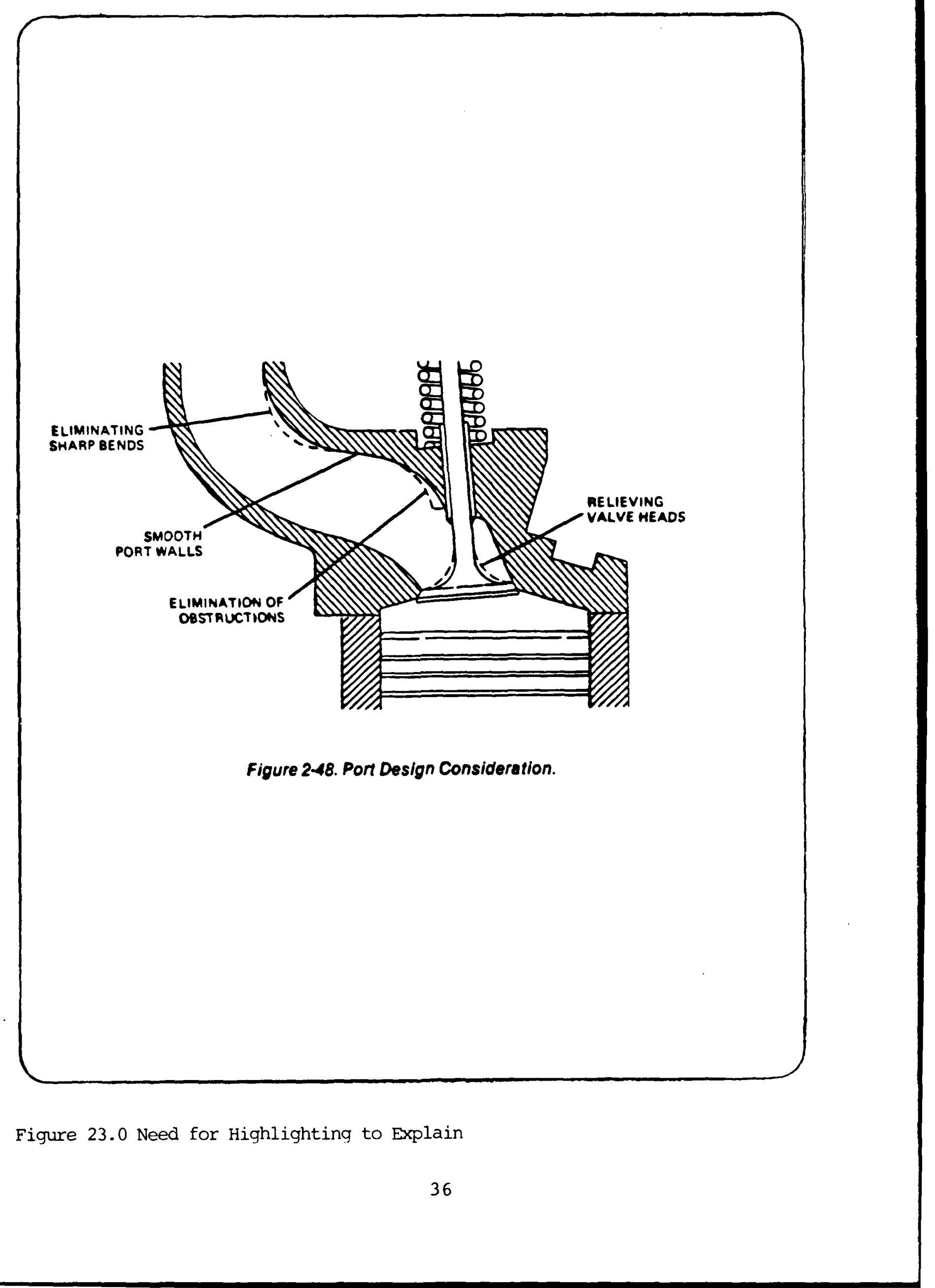


the transparency itself, we colored in the areas inside the dotted lines with a red marker pen. In Figure 24 , these areas appear dark because we can't print in color, but when projected, of course, they appear red.

Highlighting with color this way is easily done but a word of caution is necessary: Don't overdo it. Color, because of the contrast with the rest of the black and white picture, will draw immediate attention to that part of the picture, which is what you want. But if you highlight several areas of a figure, say with a couple of different colors, you lose the advantage of highlighting and divide the viewer's attention.

\section{Enlargement}

office copiers generally produce a copy which is the same size as the original while some reduce the size of the copy. A few of the copiers available in Army schools enlarge the copy, a useful tool at times. A book or manual illustration is designed to be legible at a normal reading distance but when made into a transparency and projected on a screen, legibility is often lost. The loss of legibility is most often found in the call-outs and labels as well as fine line detail. A copier which enlarges can improve the quality of such illustrations for classroom use.

An example of enlargement is shown in Figure 25 which was made by enlarging the figure we used in Figure 3. As you can see, all parts of the drawing are enlarged including the lettering of the call-outs. An enlarging copier may make it possible for you to use some small figures and illustrations which wouldn't work with a regular copier.

Miscellaneous

Even if you're not an artist, there are some things you can do to improve a visual aid. When you are preparing a figure for a transparency you use the copier twice, first to make a copy of the book or manual figure, and then to make the transparency. When you are working on the first copy it is a good idea to keep a bottle of correction fluid and a good fine-tip black pen handy. The correction fluid can be used to eliminate the extra spots and lines that often appear when using an office copier. You can use the pen to thicken iines that are too thin on your copy of the original or touch up parts that didn't copy clearly. Sometimes the lettering on call-outs is just not large enough to make a legible transparency. If the rest of the figure is clear and legible you can always cut or white out the lettering and hand-letter them with a suitable pen. 


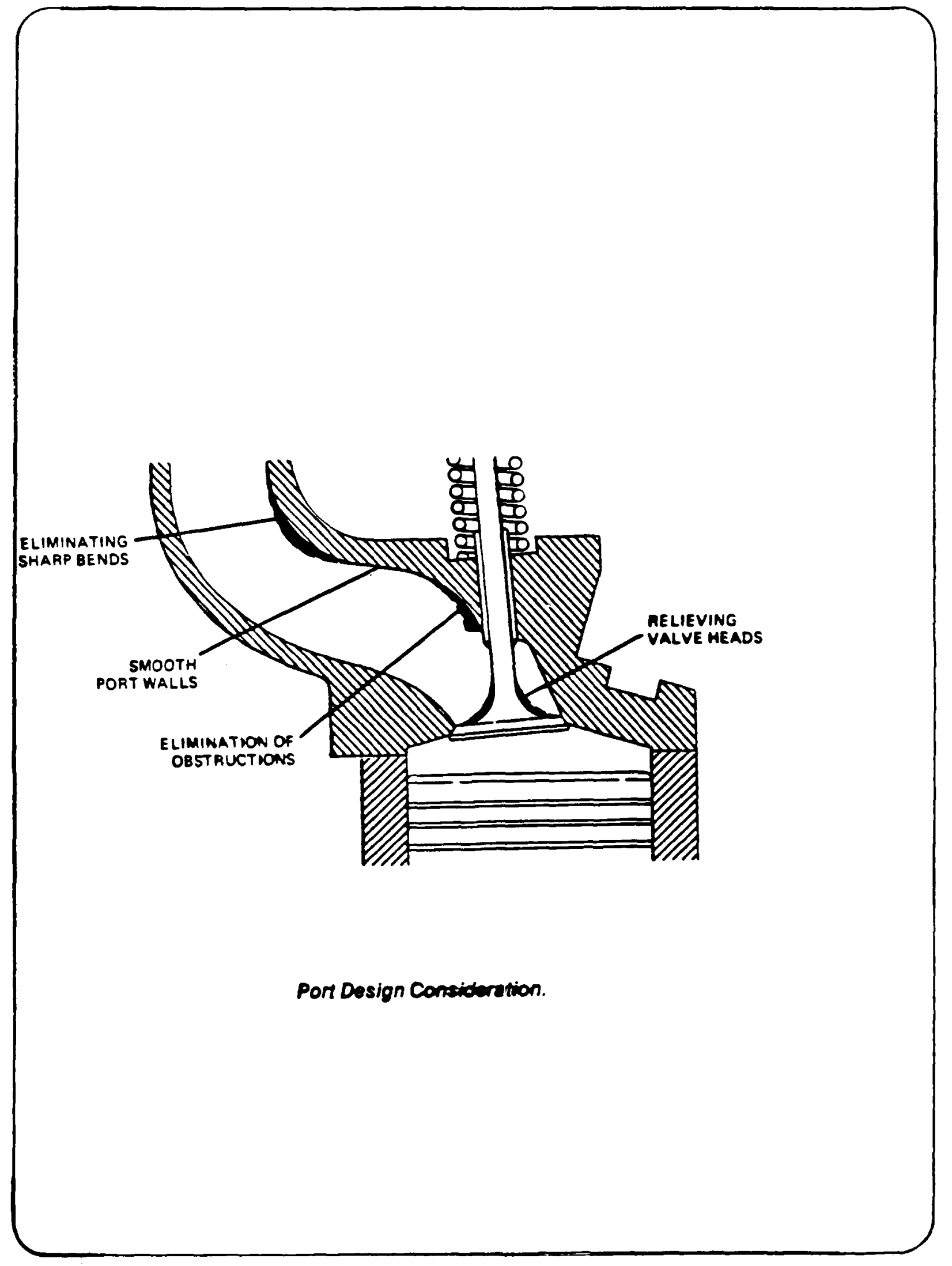

Figure 24.0 Use of Highlighting to Explain 


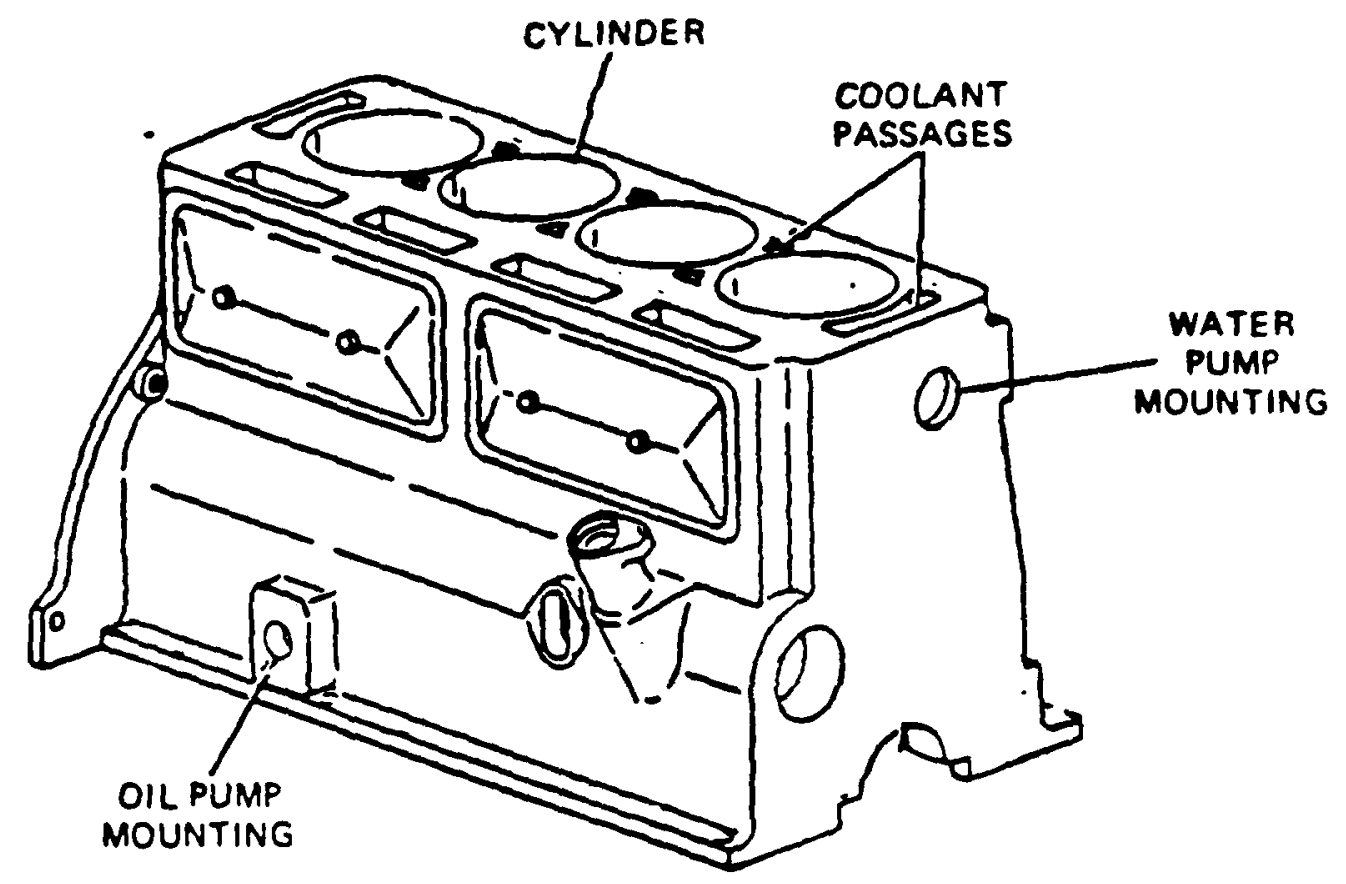

Liquid-Cooled Cylinder Block.

Figure 25.0 Book Illustration Enlarged for Clearer Viewing 
$\operatorname{TM} 9-8000$

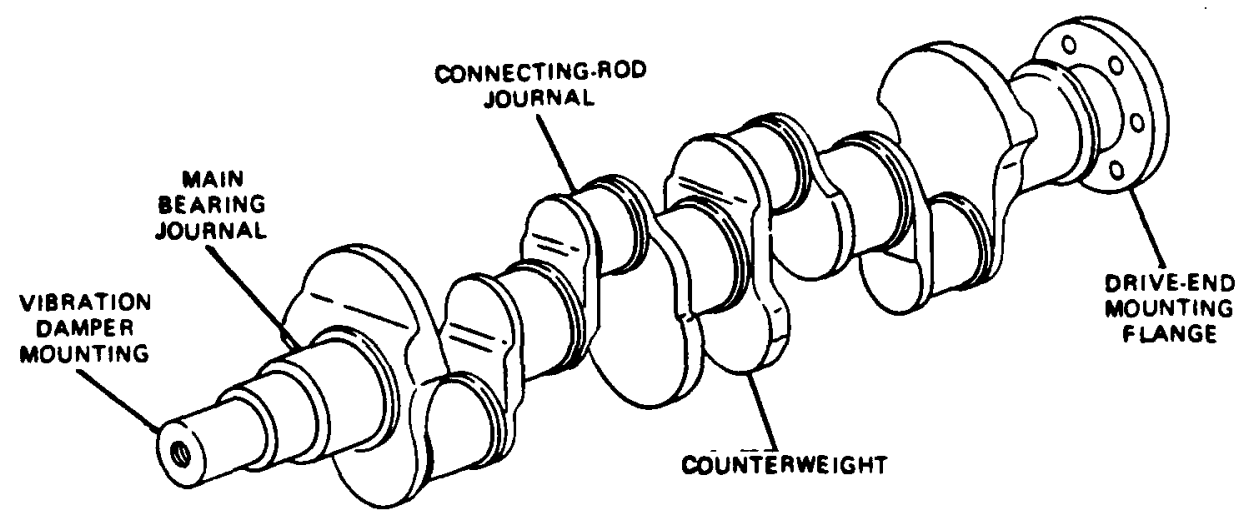

Figure 3-34. Crankshaft Construction.

vibration damper at the end of the crankshaft opposite the output end will serve to absorb torsional vibration. There are a few variations of the vibration damper, but they all accomplish their task in basically the same manner. They all employ a two-piece design. The differences in design are in how the two pieces are linked together. One type of damper links the pieces together by an adjustable friction clutch. When. ever a sudden change in crankshaft speed occurs, it causes the friction clutch to slip. This is because the outer section of the damper will tend to continue at the same speed. The slippage of the clutch serves to absorb the torsional vibration. Another type of damper links the two pieces together with rubber. As the crankshaft speeds up, the rubber compresses, storing energy. This serves to minimize the effect of crankshaft speed increase. As the crankshaft unwinds, the damper releases the energy stored in the compressed rubber to cushion the speed change in the other direction.

e. Lubrication (Fig. 3-38). The crankshaft has internal drilled passages to supply lubrication to its bearings.

\subsection{Crankshaft Bearings.}

a. General (Fig. 3-39). The crankshaft is supported in the crankcase and rotates in the main bearings. The connecting rods are sup. ported on the crankshaft by the rod bearings.

b. Construction (Fig. 3-40). Crankshaft bearings are made as precision inserts. They simply slip into place in the upper and lower halves of the shells. When the halves are clamped together, they form a precision bearing that will be a perfect fit for a properly sized shaft. The bearing inserts and the mating surface that hold them must be sized perfectly. The insent merely slips into place and is held from turning by the locatingtab.

c. Materials (Fig. 3-41). Most bearings begin with a steel backing to give them rigidity. The lining then is applied to the steel backing. The lining usually consists of an alloy of copper, tin, and lead. The lining also may be made of babbit. Babbit is a popular bearing material that is an alloy consisting of copper, tin, and antimony. The lining thickness usually ranges from 0.002 to 0.005 in. $(0.051$ to $0.127 \mathrm{~mm})$. The bearing then is coated with either aluminum or tin to a thickness of approximately 0.001 in. 10.025 $\mathrm{mm}$ ).

d. Bearing Requirements (Fig. 3-42). Bear. ings must be able to support the crankshaft rotation and deliver power-stroke thrusts under the most adverse conditions. A good bearing must have the following qualities.

(1) Strength. Engine bearings are constantly subjected to tremendous forces from the thrust of the power strokes. The bearings must be able to withstand these loads without spreading out orcracking.

(2) Corrosion. The bearing must be resistant to molsture and acids that always are present in the crankcase.

TA233370

Figure 26.0 Selecting Material for Vugraphs 
PROCEDURES

In this section we will show you how to take an illustration from some source such as a book or manual and prepare it, according to the rules and tips we've described, for making a vugraph or slide. Generally, we have made transparencies but the figure you prepare can be easily made into a $35 \mathrm{~mm}$ slide by the Training Aids or Graphic Department at the school.

\section{Materials}

Making a transparency is pretty simple. All you need is something to copy, an office copier, and some transparency film sheets that are placed in the paper tray of the copier. Preparing the figure that you will copy on the film requires only common office supplies. These include a pair of scissors, correction fluid, rubber cement, pen and pencil, and a ruler. If you want to highlight some part of the transparency with color, you can get a set of marking pens made especially for writing on transparency film.

Steps to Follow

In this section we will describe the steps to follow in making a iransparency using one of our examples to illustrate the process. The product of these steps can also be used to make a 35 man slide with the help of the Training Aid or Graphics department of the school.

\section{Select Original to Copy}

When selecting a figure to copy, you should keep in mind the rules presented in the handbook. Not all the problems associated with book or manual figures can be solved with cut-and-paste techniques, so you should study these figures carefully. Earlier, we chose a figure from TM 9-8000 to illustrate Rule \#5. Figure 26 shows the figure as it appeared in the Technical Manual. We chose this figure to illustrate how you should line up call-outs, but it also illustrates Rule \#4, which says you should limit the number of call-outs to five or less. It also reflects the main teaching point (Rule \#2) and does not contain a lot of unnecessary detail (Rule \#3).

\section{Copy Page with Original Figure.}

Actually, it is a good idea to make several copies of the original figure to use as material for your cut-and-paste 
efforts. Make sure the copies come out clean and clear.

3. Make Test Transparency

We strongly recommend that you first make a test transparency. Cut out the figure and paste it on a clean sheet of paper with rubber cement, arranging the figure the way you want the transparency to look. Figure 27 shows this step. Run off a transparency and project it on a screen. If possible, you should do this in the classroom and view it from the back of the class.

\section{Cut-and-Paste}

We decided earlier that the major change needed with this figure was to line up the call-outs. We took another copy of the figure and cut out the call-outs and the figure title and pasted the picture of the crankshaft on a clean sheet of paper. A ruler was used to maintain the proper position on the paper. We then eliminated the pointers that remained with correction fluid. Figure 28 shows the result of our work so far. Next, we cut out each of the call-outs and pasted them above and below the picture of the crankshaft so they were in a line and approximately above the part they identify. Then we pasted the titie below the picture after cutting off the TM number. Our last job was to use a ruler to make new pointers leading from the call-outs to the proper part on the figure. Figure 29 shows what the finished cut-and-paste product looks like, ready to be copied as a transparency.

\section{Make Transparency}

The final step, once you have finished all your cut-and-paste "art-work", is to make a transparency. You could also turn it over to the Training Aids department and have them make a $35 \mathrm{~mm}$ slide. Figure 30 shows what the transparency will look like. Note that if you wanted to highlight some part of the figure, say the vibration damper mounting on the left, you could use a transparency marking pen to color that part directly on the film.

\section{Project in Classroom}

The proof of the pudding, as you know, is in the eating. F-ch transparency you make should be tested in the classroom or $u$ der classroom conditions. Remember, students will be looking at that screen in the front of the class. A classroom test might reveal some thin lines which you could correct by simply thickening them on the original with a pen, or it might suggest the need for color highlighting on the transparency. It might send you back to the "drawing board" to start all over again, but that is unlikely as you gain experience. The process described 


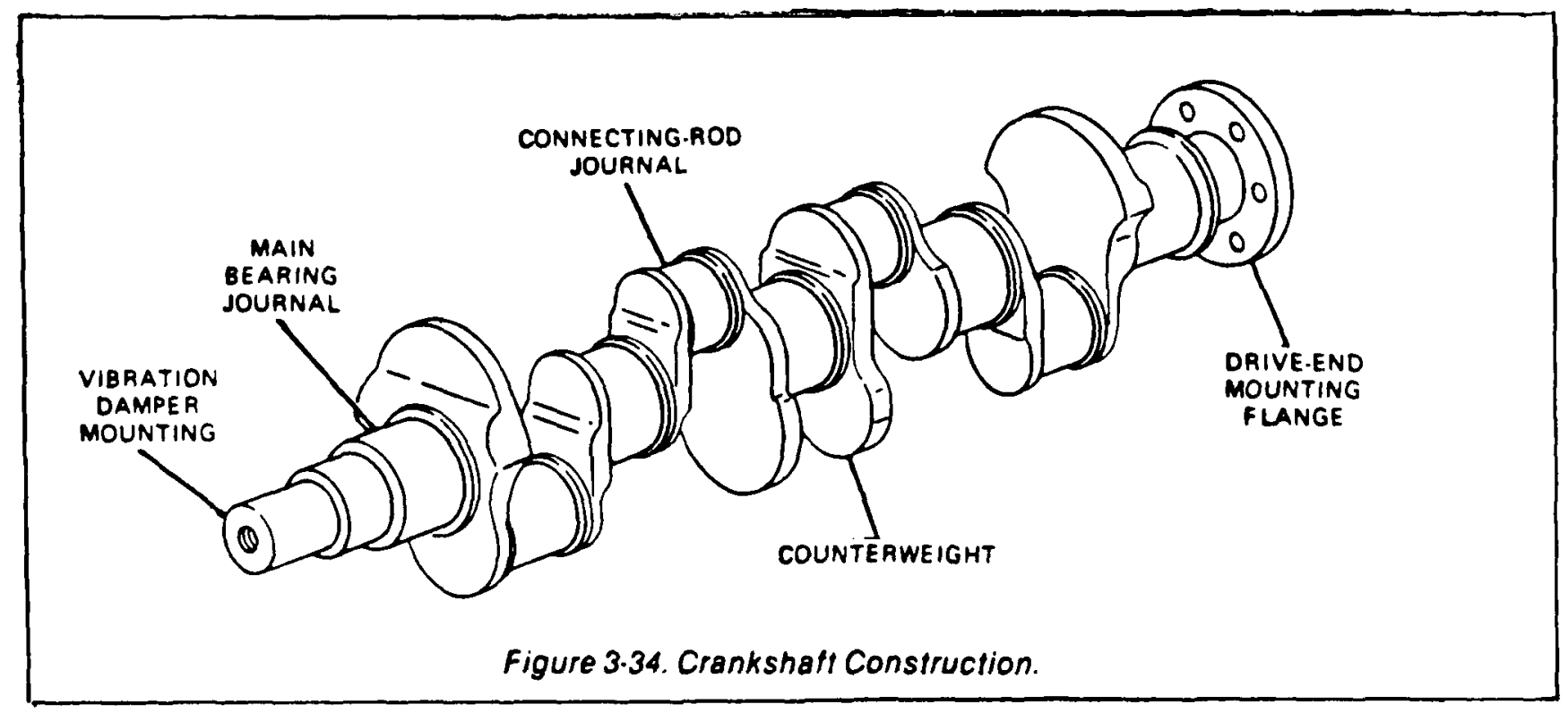

Figure 27.0 Initial cut and Paste 


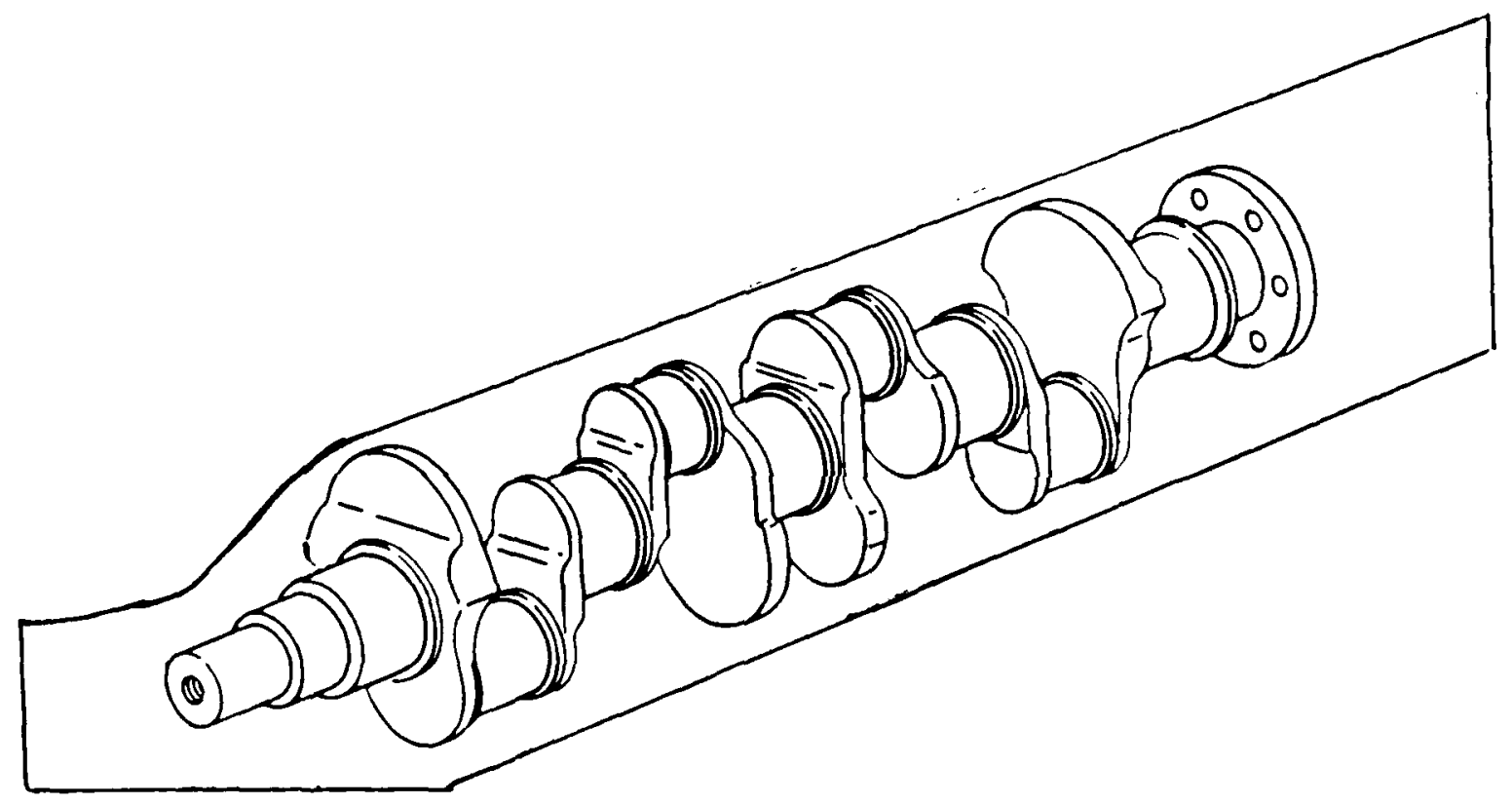

Figure 28.0 Eliminating Unwanted Materials or Arrangements 


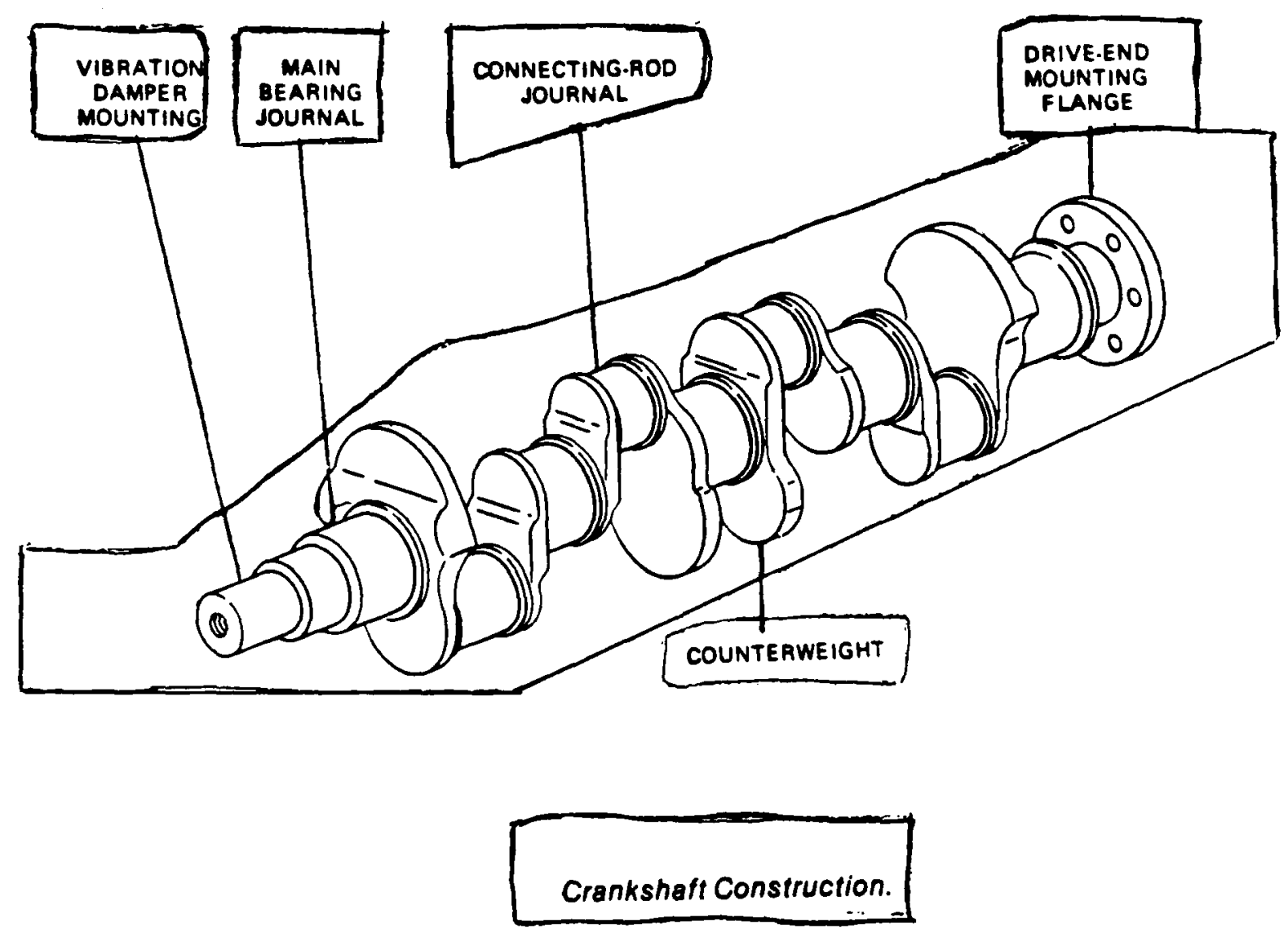

Figure 29.0 Adding New Material or Arrangements 


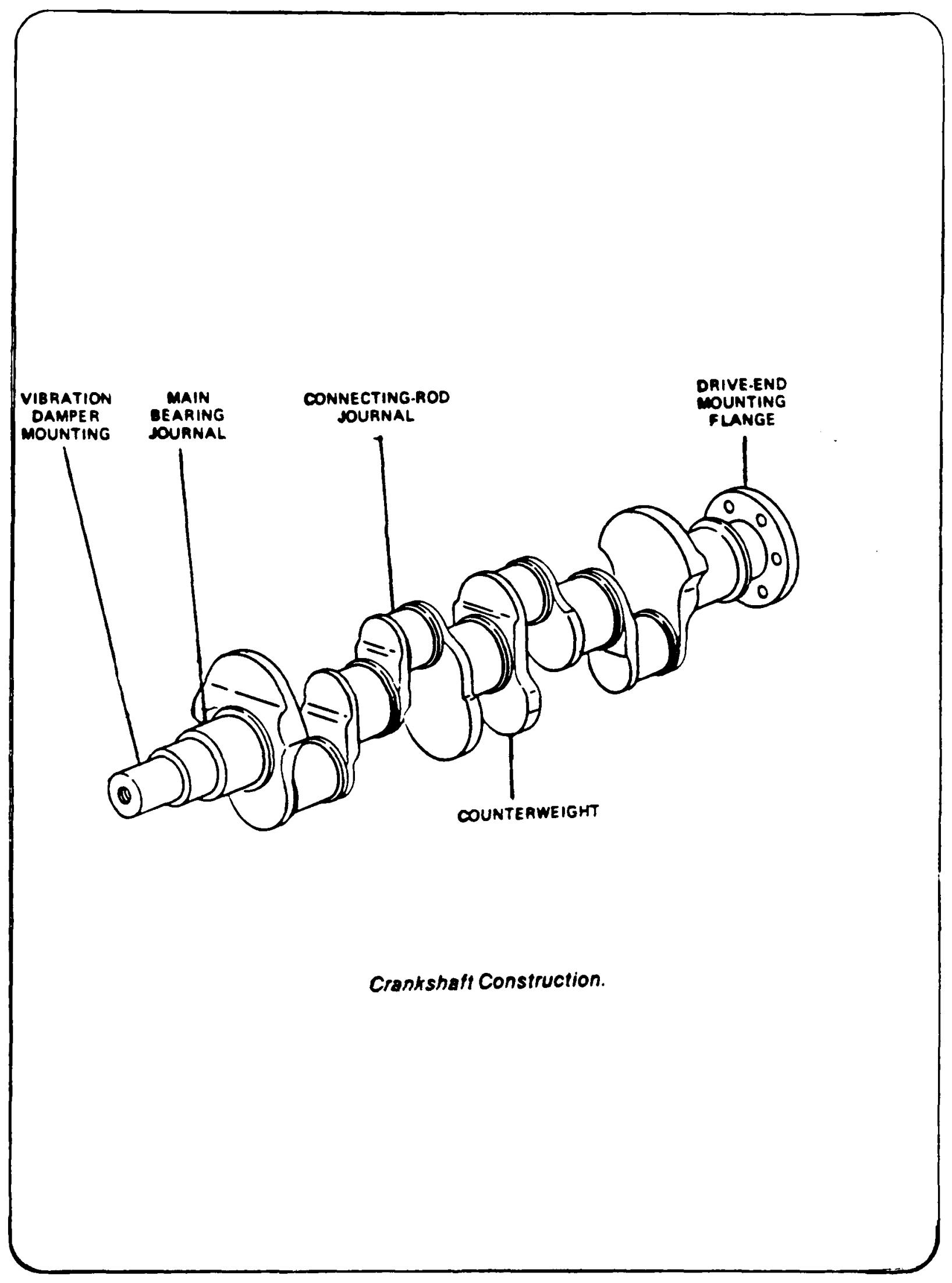

Figure 30.0 The Final Vugraph 
in this handbook may take a litule more time than simply copying a book or manual illustration but not much more time and the improvement gained is well worth the effort.

Checklist

Once you become familiar with the process of producing good vugraphs, you might want to keep a little checklist handy to remind you of the major prints we've made in this handbook. Note that the first item, although not emphasized earlier, is important for a couple of reasons. It labels the subject of the vugrapin for the student and serves as a reference for your collection of vugraphs.

\section{VUGRAPH CHECKLIST}

1.

2 .

3.

4 .

5 .

6.

7 .

Does the vugraph have an appropriate title?

Does the vugraph cover the teaching point?

Have you eliminated unnecessary detail?

Are there five or fewer call-outs?

Are the call-outs short cue words?

Are the call-outs lined up vertically or horizontally?

Have you test projected the vugraph in a classroom? 


\section{USING VISUAL AIDS EFFECTIVELY}

We will conclude with a few words about the effective use of the vugraphs or slides you have made by following this handbook. visual aids are just that, aids. They don't teach by themselves. Properly used, they can be powerful tools in the instructor's arsenal of teaching techniques. Improperly used, they can be strong distractors to effective teaching.

1. The instructor should check with the students, in class, to make sure that all parts of the visual image are clearly visible. Generally, if you have tested your material as suggested in the handbook, this shouldn't be a problem. However, graphs or slides made for one classroom may be used in another which might be larger or have a different projector. If there is any doubt that not all students can see the screen clearly, the instructor should check it out or part of the audience may be lost. Moving students forward or moving the projector to get a larger image are possible solutions. In any case, it is the instructor's business to make sure that all the students benefit from the visual aid.

2. The instructor should address only what is on the screen. The visual image commands strong attention, even if it's fuzzy or even incomprehensible! What the instructor says should direct the student to the teaching point being made by the graphic material. The students should be given time to study the screen. Extraneous lecture material, not connected to the figure or picture, probably will be ignored by most of the students. The instructor should simply describe what is in the visual aid.

The fact that the students' attention is so strongly captured by a visual display has several implications for the instructor. When the instructor is through talking about the display, it should be turned off. To leave it on and move on to new material invites loss of attention by at least part of the class. Rather than turning off the projector, some instructors affix a piece of cardboard to block off the projector lens while they change transparencies. In any case, to leave a display on while moving to a new subject is a bad idea. It is important for the instructor to remember that whatever is said is, in a sense, competing with the visual image for the attention of the student.

For some visual displays, the instructor may want to 1 imit the attention of the students tc just a portion of figure. Examples might include a list of items or steps, or a structural diagram with several sequential parts. For vugraphs, the instructor can use a sheet of paper to cover up part of the transparency and then move it to reveal each new part or step. 
3. Students in a lecture-type classroom actively participate by taking notes which is an important part of the learning process. The instructor presenting graphic material should provide time for students to copy drawings and other material into their notes. This means quiet time when the instructor is not talking. Although some instructors find this difficult, it is important if graphic material is to be effective.

4. Finally, the instructor should talk to the class and not to the screen. The instructor who turns to face the screen is usually hard to hear and has lost contact with the class and control of what is going on. 


\section{APPENDIX 1 TEACHING POINTS AND PERFORMANCE ORIENTED TRAINING}

1. The Harliss Workshop on Training Development, which has been sponsored by TRADOC at many Army schools, has some ideas which may be useful to you as you go about selecting and developing vugraphs. We'd like to summarize two of these ideas and show how you might use them.

\section{Overview.}

A vugraph can be very effective where the training developer has carefully defined its purpose and how it fits in with other parts of the POI. Equally important, the skillful training developer has focused more on "how to do things" and less on engineering descriptions of how things look and work. What results from good design practices are slides or overheads which have the right amount, kind, and layout of information (neither too much, nor too little).

2. Defining Main Teaching Points and How They Fit into the Rest of the POI.

a. Before you select or develop a drawing for a vugraph, decide what the main teaching point should be and summarize that in the title. Then analyze the specific behavior you want to teach, down to cues and actions (also called stimulus-response pairs). Let's say you want the student to be able to tell the difference between the head and block of a liquid cooled engine. More specifically you want him or her to be able to go to the shop floor, look at an engine and point to the head and block.

b. Here's how to proceed:

(1) Define the main point: e.g. "Main Parts of Liquid Cooled Engine: Head vs. Block"

(2) Analyze the main point, e.g.:

Cues

Actions

Picture of Engine Head (or actual equipment)

Picture of Engine Block (or actual equipment) student points to head and says "head"

(3) Incidently, the cue is what you expect will trigger an action. So the cues might also be the words "head" and "block" in a field manual and the responses might be "point to picture of a head in the FM". You need to decide what the student is likely to 
see first. That would be the cue. What follows the cue is the action (i.e. behavior, response).

(4) Block out the general ideas for the vugraph. We suggest that you do this before you look for graphic materials in a technical, training, or field manual. For our example, you might decide to use a simple, line drawing of an engine with two call-outs and with some shading to help separate the head from the block. Now you're in a better position to decide what figure in the manuals is appropriate and/or how that figure needs to be changed. You're also in a better position to use the rules we gave you.

(5) Decide what teaching units come before and after the one you are working on. Each vugraph that you develop is part of a larger block of instruction. You need to define carefully how it fits into the larger block, so that you build the student's skills gradually and effectively.

3. Performance-oriented Training. What does this mean and why is it important?

a. It means you teach "what to do" and "how to do". You focus on duties, tasks, and specific actions for which your students will be responsible.

b. You may have to explain what things look like or how they work but do so only as a first step followed, with a clear connection and with no delay, by "what to do" and "how to do". Theory (i.e. basic skills and knowledge) and practice should be closely integrated, not separated as it often the case with "vocational" training.

c. For example, why would you want students to recognize the head vs. block of an engine? Because the students may have to remove the head to make repairs inside the engine. Then maybe you want a vugraph with an "exploded view", e.g. head separated from the block with bolt holes and center lines. The point is that if you think in performance oriented ways, you'll come up with a variety of good ideas about how to design and use instructional vugraphs. 
1. In the handbook, we have shown you how to revise existing drawings with correction fluid and cut and paste methods. But if you have access to a graphics department, especially one with a computer, a scanning device (device for reading hard copy into a computer), and a "paint" program, you can have the department revise your drawings, very quickly and easily. For example, it can:

a. Erase labels and type in new labels which are larger and bolder.

b. Shade surfaces which need to be separated from adjacent surfaces.

c. Thicken straight lines to make them more visible.

d. Remove excess detail, even very fine detail with an "erase" and a routine called "fatbits".

2. Alternative ways to computerize graphics: The scanning device is one way to put pictures into the computer. You can also do so with a t.v. camera. You can videotape actual equipment and then have your graphics department put the resulting pictures into the computer. The department can then use a graphics program to simplify, highlight, and label the pictures. 